\title{
๖Track Deflection of Typhoon Maria (2018) during a Westbound Passage Offshore of Northern Taiwan: Topographic Influence
}

\author{
Ching-Yuang Huang, ${ }^{\mathrm{a}}$ Tzu-Chi Juan, ${ }^{\mathrm{a}}$ Hung-Chi Kuo, ${ }^{\mathrm{b}}$ And Jen-Her Chen ${ }^{\mathrm{c}}$

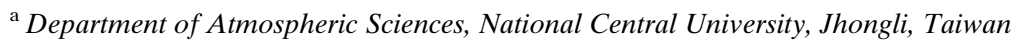 \\ ${ }^{\mathrm{b}}$ Department of Atmospheric Sciences, National Taiwan University, Taipei, Taiwan \\ ${ }^{\mathrm{c}}$ Central Weather Bureau, Taipei, Taiwan
}

(Manuscript received 16 April 2020, in final form 4 September 2020)

\begin{abstract}
This study applies a global model (FV3GFS) with stretched resolution of approximately $7 \mathrm{~km}$ for simulating Typhoon Maria (2018), which exhibited a sudden northward track deflection when approaching about $150 \mathrm{~km}$ northeast of Taiwan. As Maria approached land, the outer cyclonic flow at the western flank of the typhoon is split around the northern part of the Central Mountain Range (CMR) in Taiwan to converge east of Taiwan with the recirculating southerly flow around the southern corner of the CMR. Such strong convergence leads to northward deflection of the west-northwestward-moving typhoon with the stronger wind mainly east of the vortex center. The radial inflow at low levels is intensified south of the vortex center and transports larger angular momentum (AM) inward with the enhanced upward motions and vertical mean AM advection to increase the azimuthal mean tangential wind in the lowertropospheric eyewall. A vorticity budget of wavenumber-1 decomposition indicates that the track deflection is dominated by horizontal vorticity advection in response to the intensifying flow. Numerical experiments with idealized WRF also support such northward track deflection as westward tropical cyclones approach a mountain range within an offshore meridional distance of about $200 \mathrm{~km}$. The northward track deflection is only slightly amplified as the terrain height is considerably increased, consistent with the real-case simulation. However, the northward track deflection is not increased as the approaching vortex is initialized closer to the northern end of the mountain range, due to the enhanced east-west symmetry of wind structure in the inner vortex.
\end{abstract}

KEYWORDS: Numerical analysis/modeling; Numerical weather prediction/forecasting

\section{Introduction}

It has not been rare to observe large track variations of tropical cyclones translating past an isolated high mountain or a mountain range over 3000-m height, such as the Central Mountain Range (CMR) in Taiwan Island over the western North Pacific (WNP), Réunion Island over the Indian Ocean east of Madagascar, and Hawaii's Big Island (e.g., Chambers and Li 2011; Hsu et al. 2018; Barbary et al. 2019). Tropical cyclones moving past an isolated mountain range like the CMR have been widely investigated using observations and numerical models, and more recently with great attention to the track deflection prior to and after landfall at the mountain (e.g., Jian and Wu 2008; Lin and Savage 2011; Huang et al. 2011; Chien and Kuo 2011; Hsu et al. 2013, 2018; Wu et al. 2015; Tang and Chan 2016a,b; Huang et al. 2016, 2019, 2020; Lin et al. 2016; Huang and Wu 2018). Significant modifications of the track of an approaching tropical cyclone can be induced as topographical effects of a mesoscale mountain not only modulate the core structure of the cyclone but also the environmental steering flow in which the cyclone is embedded. Among typhoons approaching from different directions in 1958-2019,

\footnotetext{
D Denotes content that is immediately available upon publication as open access.
}

Corresponding author: Prof. Ching-Yuang Huang, hcy@atm.ncu. edu.tw about two-thirds of the typhoons passed over or around Taiwan from the east according to the Typhoon Database of the Central Weather Bureau (CWB) in Taiwan. In addition, about three-fourths of the typhoons directly crossing Taiwan were moving westward and associated with appreciable track variations (e.g., Chang et al. 2013; Chen et al. 2017). Some of them made landfall north of the central latitude of the CMR and in fact were associated with larger track variations east of the CMR than those with landfall to the south (e.g., Hsu et al. 2018).

About one quarter of the westbound typhoons moving toward Taiwan actually took paths across northern Taiwan or around the northern tip of the island at some offshore distance. As the westbound typhoons are approaching near offshore of northern Taiwan, appreciable track deflection can also be identified as well. Figure 1 shows all the historical typhoons in the past 50 years associated with northward track deflection near offshore of northern Taiwan, including Nelson (1985), Sinlaku (2002), Wipha (2007), Trami (2013), Maria (2018), and Lekima (2019). The typhoon movement can be westward, west-northwestward, or northwestward at some offshore distances from the northern coast of Taiwan. As the typhoon moves closer to northern Taiwan, its track may present a counterclockwise turn, as marked by a red dashed circle, at a curvature scale comparable to the width of the CMR. It should be noted that similar track deflection may also occur farther upstream between $126^{\circ}$ and $128^{\circ} \mathrm{E}$ in Lekima's track (Fig. 1f), but such deflection is more likely to occur due to interaction with the environmental flow, not with the CMR. For Typhoon 

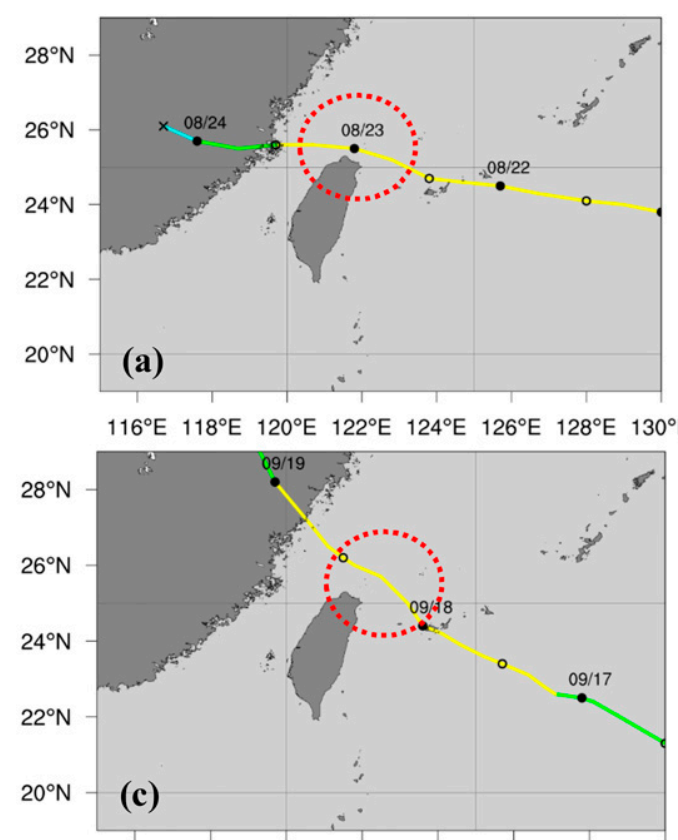

$116^{\circ} \mathrm{E} \quad 118^{\circ} \mathrm{E} \quad 120^{\circ} \mathrm{E} \quad 122^{\circ} \mathrm{E} \quad 124^{\circ} \mathrm{E} \quad 126^{\circ} \mathrm{E} \quad 128^{\circ} \mathrm{E} \quad 130^{\circ} \mathrm{E}$

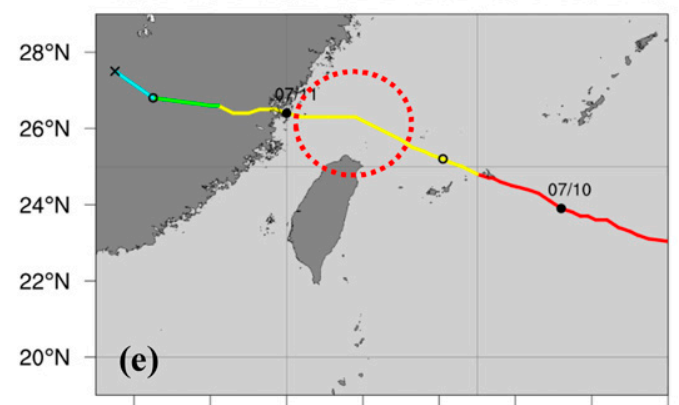

$116^{\circ} \mathrm{E} 118^{\circ} \mathrm{E} 120^{\circ} \mathrm{E} 122^{\circ} \mathrm{E} 124^{\circ} \mathrm{E} 126^{\circ} \mathrm{E} 128^{\circ} \mathrm{E} 130^{\circ} \mathrm{E}$
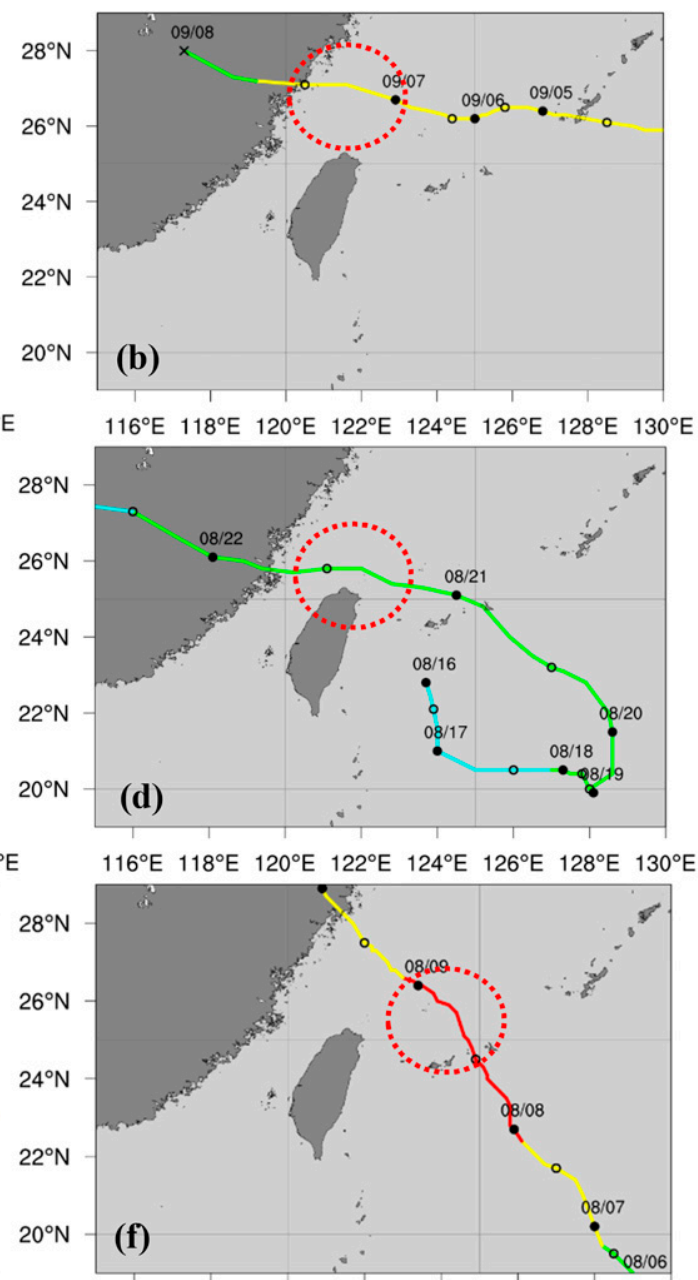

$116^{\circ} \mathrm{E} 118^{\circ} \mathrm{E} 120^{\circ} \mathrm{E} 122^{\circ} \mathrm{E} 124^{\circ} \mathrm{E} 126^{\circ} \mathrm{E} 128^{\circ} \mathrm{E} 130^{\circ} \mathrm{E}$

FIG. 1. Typhoons with northward track deflection near offshore of north Taiwan: (a) Nelson (1985), (b) Sinlaku (2002), (c) Wipha (2007), (d) Trami (2013), (e) Maria (2018), and (f) Lekima (2019). Typhoon intensity in the track is indicated by colored segment in red (intense typhoon), yellow (moderate typhoon), green (tropical storm), and blue (tropical depression). The red dashed circle highlights the segment of the track with appreciable deflection that may be influenced by the topographic effect of Taiwan terrain.

Maria, the track far upstream of Taiwan is rather straight westnorthwestward (Fig. 1e) and thus the induced track deflection near offshore of northern Taiwan may be influenced by topographic effects of the CMR when Maria is closer to Taiwan terrain. Understanding of such induced track deflection is important for forecasters in order to make a reliable decision for the storm impacts.

To forecast and investigate the track and intensity evolution of tropical cyclones, multiple-resolution global models have been implemented at academic institutes and operational forecast centers. For hurricanes over the North Atlantic, the global model fvGFS of the Geophysical Fluid Dynamics Laboratory (GFDL) equipped with the finitevolume cubed-sphere dynamical core (FV3) has exhibited reasonable capability with a finest resolution of $2 \mathrm{~km}$ for hurricane structural forecasts (Hazelton et al. 2018a) and reliable prediction skill with global $13-\mathrm{km}$ resolution for hurricane track forecasts (Chen et al. 2019). FV3 has been implemented into the Next Generation Global Prediction System (NGGPS) to combine with the Global Forecast System (GFS) for daily operation at $13-\mathrm{km}$ resolution at the National Centers for Environmental Prediction (NCEP). Variable-resolution capability of FV3-based GFS (i.e., FV3GFS) has advanced the prediction skill of extreme precipitation over the southern Great Plains of the United States compared to uniform-resolution simulations (Zhou et al. 2019). For local severe weather prediction, FV3GFS will also be used at CWB as the next generation global model for forecasts of typhoons over the WNP. The built-in capability of nested as well as stretched grids of FV3 (Hazelton et al. 2018b) provides a great opportunity to investigate the structural change and track evolution of typhoons impinging on Taiwan, with enhanced higher-resolution in the regions of storm path and high topography. 
Complementary to the real-case forecasts, idealized modeling has been utilized to help identify the dynamic processes associated with the track variations of translating tropical cyclones past a mountain range (e.g., Chang 1982; Bender et al. 1987; Yeh and Elsberry 1993a,b; Huang et al. 2011, 2016; Lin et al. 2005, 2016; Lin and Savage 2011; Tang and Chan 2016a,b; Hsu et al. 2013, 2018; Huang and Wu 2018). Simulated westward cyclone tracks tend to exhibit upstream northward or southward deflection when the cyclones are approaching the northern or southern part of the mountain range, in agreement with the observations (e.g., Yeh and Elsberry 1993a; Huang and $\mathrm{Wu}$ 2018). The upstream northward or southward track deflection is mainly attributed to the northward and southward splitting of the environmental steering flow at low levels ahead of the mountain with appreciable blocking effects. Near landfall, the deflected track to the north may rebound southward ahead of the mountain (e.g., Huang et al. 2011; Wu et al. 2015; Huang et al. 2016; Tang and Chan 2016b; Huang and Wu 2018).

Idealized experiments have shown that the upstream track deflection for westbound cyclones toward the central peak of a mountain range is intimately controlled by the dominant factor $R / L_{y}$ (the nondimensional vortex size) with $R$ (the radius of the maximum tangential wind of the initial vortex) and $L_{y}$ (the mountain length scale in the direction normal to the vortex movement)(Lin et al. 1999, 2002, 2005; Huang et al. 2016). As westbound cyclones pass near or over the idealized central mountain range, southward track deflection can be specifically induced in response to the channeling effects with stronger northerly flow at low levels ahead of the mountain and the midtropospheric accelerating northerly flow over the mountain range (e.g., Wu et al. 2015; Huang et al. 2016). For a northwestward moving vortex approaching northern Taiwan, southward track deflection ahead of the mountain may also be produced by the effect of differential latent heating over the northern CMR (Hsu et al. 2018). However, there are few studies on the track deflection when westbound cyclones are not approaching toward the major part of the mountain but at some offshore meridional distances. For this case, flow recirculating around the mountain corner rather than upstream blocking and flow channeling near the central mountain should play a more important role in the upstream track deflection if any. Tang and Chan (2016b) applied idealized WRF simulations to investigate the track deflection of a northwestward moving vortex passing offshore around northern Taiwan. In this study, we also applied idealized WRF simulations to emulate the observed track deflection of Maria and help explore the sensitivity of the track deflection to offshore positions of the approaching cyclone as well as its initial intensity.

This paper is organized as below. Numerical aspects are given in section 2 to introduce the global model and real-case experiments conducted in this study. Simulated results of FV3GFS are presented and compared with the observations in section 3. Section 4 presents dynamic aspects including angular momentum and vorticity budget analyses of the evolving typhoon structure and discussions on topographic influence of Taiwan terrain on the track deflection of Maria. Idealized WRF with simplified Taiwan terrain was also applied to verify the track deflection mechanism of Maria in section 5. Both idealized WRF and numerical experiments are described in this section. Finally, conclusions are given in section 6 .

\section{Numerical aspects}

\section{a. The global model}

The global model FV3GFS was applied to simulate Typhoon Maria in this study. FV3GFS is the updated nonhydrostatic version of HIRAM developed at GFDL based on the dynamic core FV3 (Lin and Rood 1997; Lin 1997, 2004) and was implemented into NGGPS at NCEP for global operational forecast with GFS physics packages. Treatment of vertical advection using a flux-form semi-Lagrangian algorithm (Lin and Rood 1996) enhances the accuracy and efficiency of the model prediction. The cubed sphere of FV3 removes the singular polar point of a global spectral model (Putman and Lin 2007) and allows a more uniform global horizontal resolution. FV3 enables nesting specific faces as well as stretching the cubed sphere so that higher resolution can be used in any targeted face of interest. Figure 2 gives an example of regular and stretched cubed spheres of FV3, denoted as grid meshes of C768T (unstretched) and C768Tr20 (stretched), respectively. C768T with $768 \times 768$ grids in each cube offers a horizontal resolution of about $13 \mathrm{~km}$ near the center of each face, while C768Tr20 allows a stretching of the grids to gradually enhance the horizontal resolution to about $7 \mathrm{~km}$ near the central region of the targeted face (Harris and Lin 2013; Harris et al. 2016). For unstretched meshes, the resolution is slightly increased toward the edge of each face to reduce the computational errors. With the local resolution enhancement, FV3 may be advantageous for predictions of severe weather (like typhoons and mesoscale convective systems) near complex terrain that require higher horizontal resolution to better resolve the topographic effects and the structural evolution of the weather systems (Zhou et al. 2019).

\section{b. The numerical experiments}

Since Typhoon Maria moved near offshore of northern Taiwan, in the current study we have employed the grid stretching on the face centered at $24^{\circ} \mathrm{N}$ and $121^{\circ} \mathrm{E}$ (central Taiwan) with the C768Tr20 mesh as shown in Fig. 2b. The GFDL cloud microphysics scheme is used, which is a singlemoment scheme of six hydrometeor species based on Lin et al. (1983). There are total of 63 vertical layers in a hybrid-pressure terrain-following coordinate with a top of $1 \mathrm{hPa}$. The NCEP Global Data Assimilation System (GDAS) analysis data at horizontal resolution of $0.25^{\circ} \times 0.25^{\circ}$ are used for interpolation to provide the initial condition of FV3GFS. During the model integration of $54 \mathrm{~h}$, the sea surface temperature from GDAS is unchanged. The control experiment uses C768Tr20, denoted as CTL (stretched), compared to C768T (unstretched). To explore the influence of Taiwan terrain, the whole Taiwan Island is completely removed in an experiment (denoted as noT) for comparison with CTL. We also conducted sensitivity experiments, H0, H50, and H130, where only Taiwan terrain height is multiplied by $0 \%, 50 \%$, and $130 \%$, respectively, but with unchanged category of land and sea. The model output is 


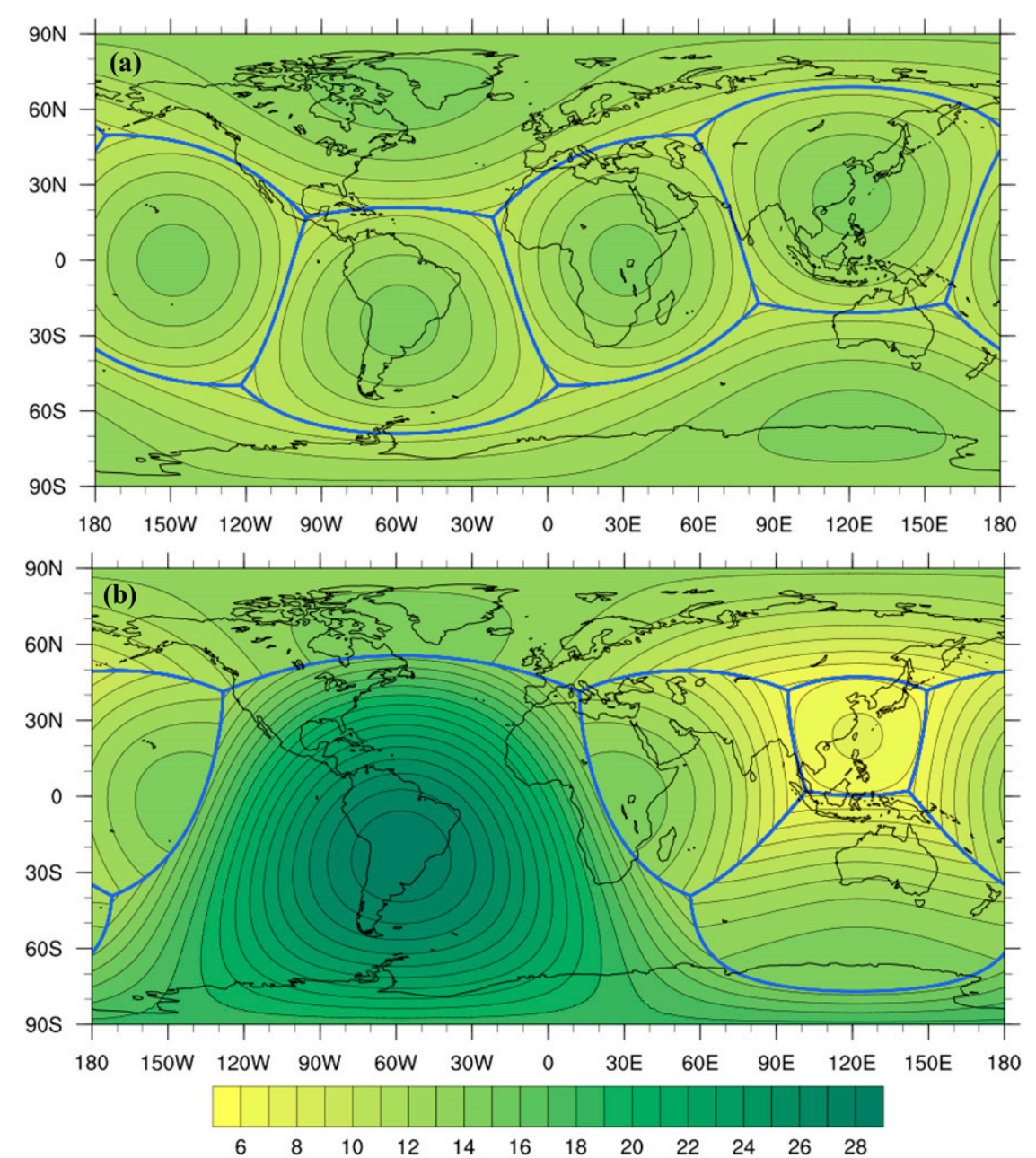

FIG. 2. (a) C768T grid mesh of FV3GFS with one face centered on Taiwan of about 13-km resolution. (b) As in (a), but for C768Tr20 with stretched grids at the highest resolution of about $7 \mathrm{~km}$ in the vicinity of Taiwan. Shaded colors and contours indicate the horizontal resolution $(\mathrm{km})$.

interpolated to the latitude and longitude coordinates at $0.125^{\circ} \times 0.125^{\circ}$ and a uniform vertical resolution of $200 \mathrm{~m}$ for analysis.

\section{c. Azimuthal-mean angular momentum budget}

To investigate the structural evolution of the typhoon near the topography, an azimuthal-mean angular momentum (AM) budget in cylindrical coordinates is diagnosed in this study. The governing equation for the azimuthal-mean AM budget is given in the appendix.

\section{d. Vorticity budget and regressed translation}

A vorticity budget helps identify the relative importance of different physical processes in influencing the movement of the vortex. We utilized the decomposed vorticity budget to estimate the translation velocity of the vortex. The regression method (Wu and Wang 2000) can be applied to provide reasonable estimation on the contribution of each physical process to vortex translation based on the decomposed wavenumber-1
(WN-1) vorticity tendency. Formulations of the vorticity equation and regression method are given in the appendix of Huang et al. (2017). A WN-1 vorticity budget averaged from 1- to $8-\mathrm{km}$ height within a specified radius of the vortex center is analyzed. In this study, the radius is chosen as $5^{\circ}$ for the vortex.

\section{Simulation results of Maria}

\section{a. Track forecast sensitivity to initial time}

Forecasts of Maria at several lead times were conducted to explore the capability of FV3GFS in capturing the track deflection. The typhoon track herein is traced using the position of minimum sea level pressure. The forecast at a lead time of 6 July 2018 gives a large northward bias at earlier times as shown in Fig. 3a. Such bias is greatly reduced at lead times of 7 and 8 July, but still with noticeable deviations from the best track after 10 July. At the initial time of 9 July, FV3GFS obtains a rather consistent track with northward track 


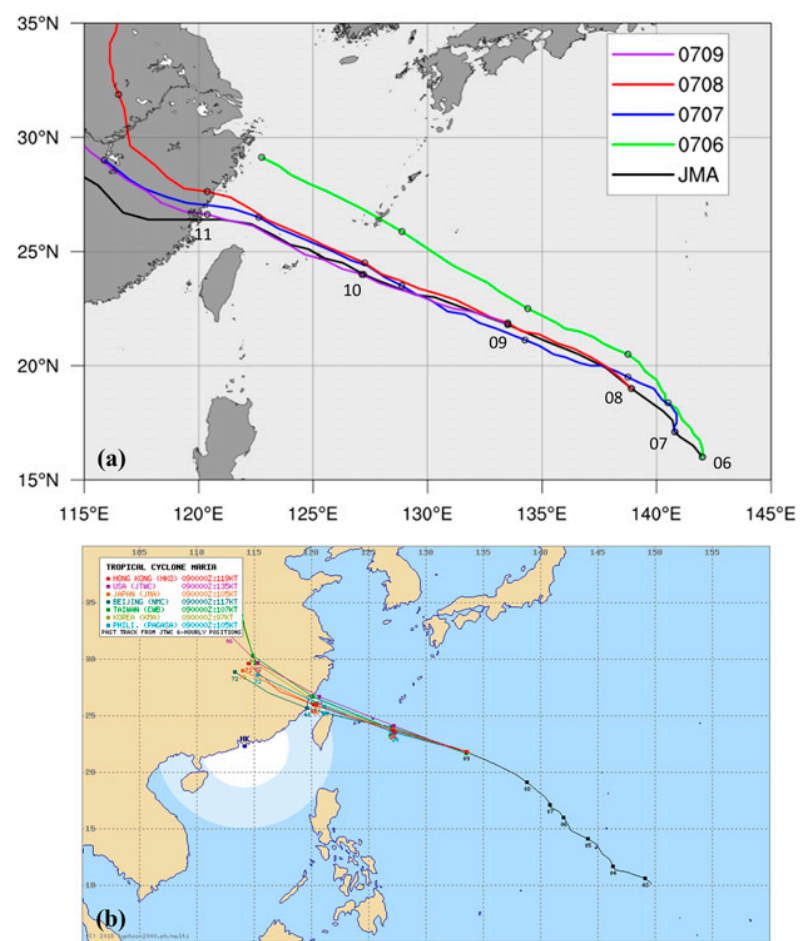

FIG. 3. (a) FV3GFS 96-h tracks of Typhoon Maria with C768Tr20 at different lead times from 0000 UTC 6-9 Jul and the best track from JMA with the circles in the tracks indicating an interval of $24 \mathrm{~h}$. (b) Track forecasts starting from 0000 UTC 9 Jul at several operational centers. The numbers in (a) indicate the best track times. (Available from http://www.typhoon2000.ph/multi/ log.php?name=Maria_2018.)

deflection near offshore of northern Taiwan, although the forecasted track when closer to mainland China is less westward than the best track. At the same lead time, most of the operational forecasts tend to produce southward-biased tracks (Fig. 3b). Failure in capturing the more northward track of Maria with induced deflection near northern Taiwan for the CWB official forecast resulted in a false alarm that exaggerated the storm impacts on northern Taiwan. For the purpose of investigating the induced track deflection, the FV3GFS forecast at the lead time of 9 July will be used for analyses presented later.

\section{b. Track and intensity forecasts with and without the terrain}

Figure 4 shows the simulated tracks for CTL, noT, and C768T and the best track of the Japan Meteorological Agency (JMA) as well as the time evolution of their maximum typhoon intensities from 0000 UTC 9 July 2018 . The best track data from CWB are also shown for intensity comparisons. Compared to C768T with $13-\mathrm{km}$ resolution, the stretched grid mesh of $\mathrm{C} 768 \mathrm{Tr} 20$ with approximately $7-\mathrm{km}$ resolution slightly improves the track prediction by reducing the southward deviation before $36 \mathrm{~h}$ (i.e., 1200 UTC 10 July), and increasing the track deflection afterward (Figs. 4a,b). Note that the improvement on track forecast with the enhanced horizontal resolution may not be robust as it can be affected by many other factors. Using the enhanced resolution, the CMR is better resolved with a maximum height over
$3 \mathrm{~km}$ (Fig. 4b). Both the simulated tracks are in good agreement with the best track from JMA, indicating that $13-\mathrm{km}$ resolution is still reasonable for typhoon track prediction. In the absence of Taiwan terrain in noT, the typhoon moves straight westnorthwestward without any detectable deflection when closing near offshore of northern Taiwan. The close-up tracks for CTL and noT indicate that the track deflection takes place from 36 to $45 \mathrm{~h}$ (from the beginning to the rebounding end) with the length scale of about $200 \mathrm{~km}$, which is roughly 2 times the width of the CMR along the track.

Compared to the best track data from CWB, the simulated typhoon maximum wind speeds at the lowest model level (near 20-m height) for CTL and noT (Fig. 4c) agree well with the best track data before $33 \mathrm{~h}$, but are slightly overpredicted after $36 \mathrm{~h}$ (the commencement of track deflection). Note that in the surface layer (assumed with vertically increased logarithmic wind speeds), the predicted wind speed at 20-m height will be slightly larger than at $10-\mathrm{m}$ height at which the best track wind is estimated. The maximum wind speed from the best track data of JMA is about 1-5 $\mathrm{m} \mathrm{s}^{-1}$ lower than that from CWB. C768T with unstretched grids in general obtains the maximum wind intensity about 2-4 $\mathrm{m} \mathrm{s}^{-1}$ weaker than those for both CTL and noT with stretched grids. It is interesting to observe that the maximum wind for CTL is about $2-7 \mathrm{~m} \mathrm{~s}^{-1}$ stronger during the track deflection $(36-45 \mathrm{~h})$ and becomes slightly weaker after $45 \mathrm{~h}$ and before $54 \mathrm{~h}$ (the end of the forecast) as compared to noT. The simulated central sea level pressure (CSLP) during the track deflection for CTL is between JMA and CWB (the latter about $20 \mathrm{hPa}$ deeper) (Fig. 4d). Although radar measurement was conducted near the northeastern tip of Taiwan by CWB to estimate the typhoon intensity, there was no dropsonde data for verifying which estimation is closer to the truth. For intensity forecasts in CTL, FV3GFS has given reasonable performances with stretched grids. The simulated typhoon intensity for $\mathrm{C} 768 \mathrm{~T}$ is underpredicted by $36 \mathrm{~h}$ and is somewhat weaker than CTL, but its associated surface maximum wind from 36 to $51 \mathrm{~h}$ is better predicted than CTL. Consequently, the simulated track deflection for C768T is comparable to that for CTL.

\section{c. Track forecast sensitivity to physics schemes}

The track deflection in the presence of Taiwan terrain for CTL in Fig. 4b appears to be a small deviation from that without Taiwan terrain. One may wonder whether such track deflection can be systematically induced for Maria when approaching offshore of northern Taiwan. Figure 5 shows the simulated tracks in the vicinity of northern Taiwan for the sensitivity experiments conducted as CTL but with different cloud microphysics and convection parameterization schemes. Cloud microphysics schemes include a scheme similar to that of Lin et al. (1983) (used in CTL) and the WRF single-moment 6-class scheme (WSM6), and the Thompson scheme (which is a partial double-moment scheme). For cloud convection parameterization, there are 2010 and 2017 shallow and deep convection schemes for FV3FGS (for details, see Hazelton et al. 2018a). The 2010 deep convection scheme (Han and Pan 2011) is a simplified Arakawa-Schubert (SAS) scheme that was upgraded to the scale-aware mass-flux (SAMF) deep convection scheme in 2017 (Han et al. 2017). The 2010 shallow convection scheme is essentially a part of SAS that 

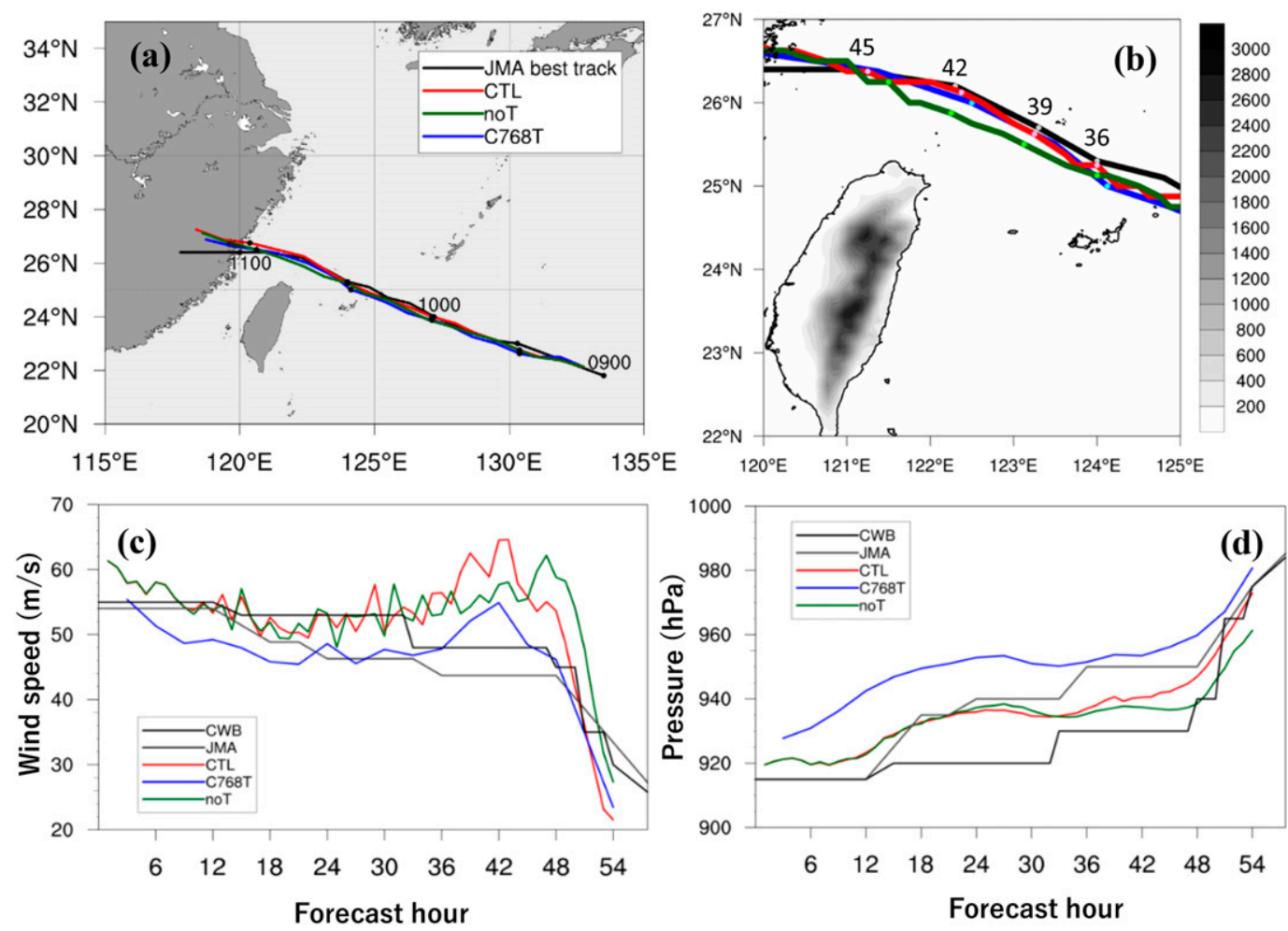

FIG. 4. (a) The simulated tracks for CTL (red), noT (green), and C768T (blue), and the JMA best track (black). (b) As in (a), but for a close-up with forecast hours labeled. (c) Simulated maximum wind speed $\left(\mathrm{m} \mathrm{s}^{-1}\right.$ ) with forecast time at the model surface level for CTL (red), noT (green), C768T (blue), and the best track data from JMA (brown) and CWB (black) with time. (d) As in (c), but for central sea level pressure (hPa). The shading in (b) indicates Taiwan topography with height scale $(\mathrm{m})$ to the right.

was also upgraded to the SAMF shallow convection scheme (Han et al. 2017). All the forecasts with and without Taiwan terrain give almost overlapped tracks prior to the deflection (only the track segment near northern Taiwan is presented for clarity). There is evidence that northward track deflection can be induced in all the experiments as the typhoon vortex moves closer to northern Taiwan. As noted, a southward-biased track prior to the deflection seems to be associated with a less northward deflection as seen in Figs. $5 \mathrm{~b}$ and $5 \mathrm{c}$. The track deviations with and without Taiwan terrain in Figs. 4b and 5 support that the track deflection associated with Maria can be systematically induced by Taiwan terrain despite that the deflection magnitude may be somewhat sensitive to physical processes involved in the evolving typhoon during the interaction with the terrain. It is noted that both interval variability of the evolving cyclone and systematic uncertainty of physics parameterization also affect the track deflection. We will apply an idealized WRF model to help realize whether the observed track deflection and its magnitude can be reproduced by the idealized experiments with similar terrain and a moving vortex.

\section{d. Typhoon circulation}

Simulated typhoon circulations at $850 \mathrm{hPa}$ at 36 and $39 \mathrm{~h}$ for CTL and noT are shown in Fig. 6. At $36 \mathrm{~h}$, Maria is about $200 \mathrm{~km}$ east of the northern coast of Taiwan in association with a rather circular inner vortex, except for the southern flank of the vortex that has been considerably influenced by Taiwan terrain (Fig. 6a). A more intense core in the inner vortex is present to the northeast of the vortex center to produce asymmetric wind along the west-northwestward direction following the typhoon movement at this time. The outer cyclonic flow of Maria farther west of the vortex center is split by the northern CMR, providing the western branch that moves southward along the west coast of Taiwan, then passes around the southern corner of the CMR and becomes southwesterly to southerly east of Taiwan and south of the vortex center. At $39 \mathrm{~h}$, Maria is approaching closer and near offshore northeast of Taiwan. The intense core of the inner vortex becomes slightly stronger than at $36 \mathrm{~h}$ and the southwesterly flow becomes further intensified and more southerly to the south of the vortex center and east of Taiwan (Fig. 6b). The westerly flow at the southwest quadrant of the inner vortex converges with the outer intense southerly flow mainly at the southeast quadrant. The typhoon circulations for CTL and noT in general are similar at $36 \mathrm{~h}$, but the associated recirculating flow east of Taiwan and vortex core at the eastern flank for noT are considerably weaker at $39 \mathrm{~h}$ than those for CTL (Figs. 6e,f). At this time, the track deflection only takes place when Taiwan terrain is present.

The associated vertical motions for CTL are rather symmetric about the vortex center at $36 \mathrm{~h}$ (Fig. 6c) but becomes 

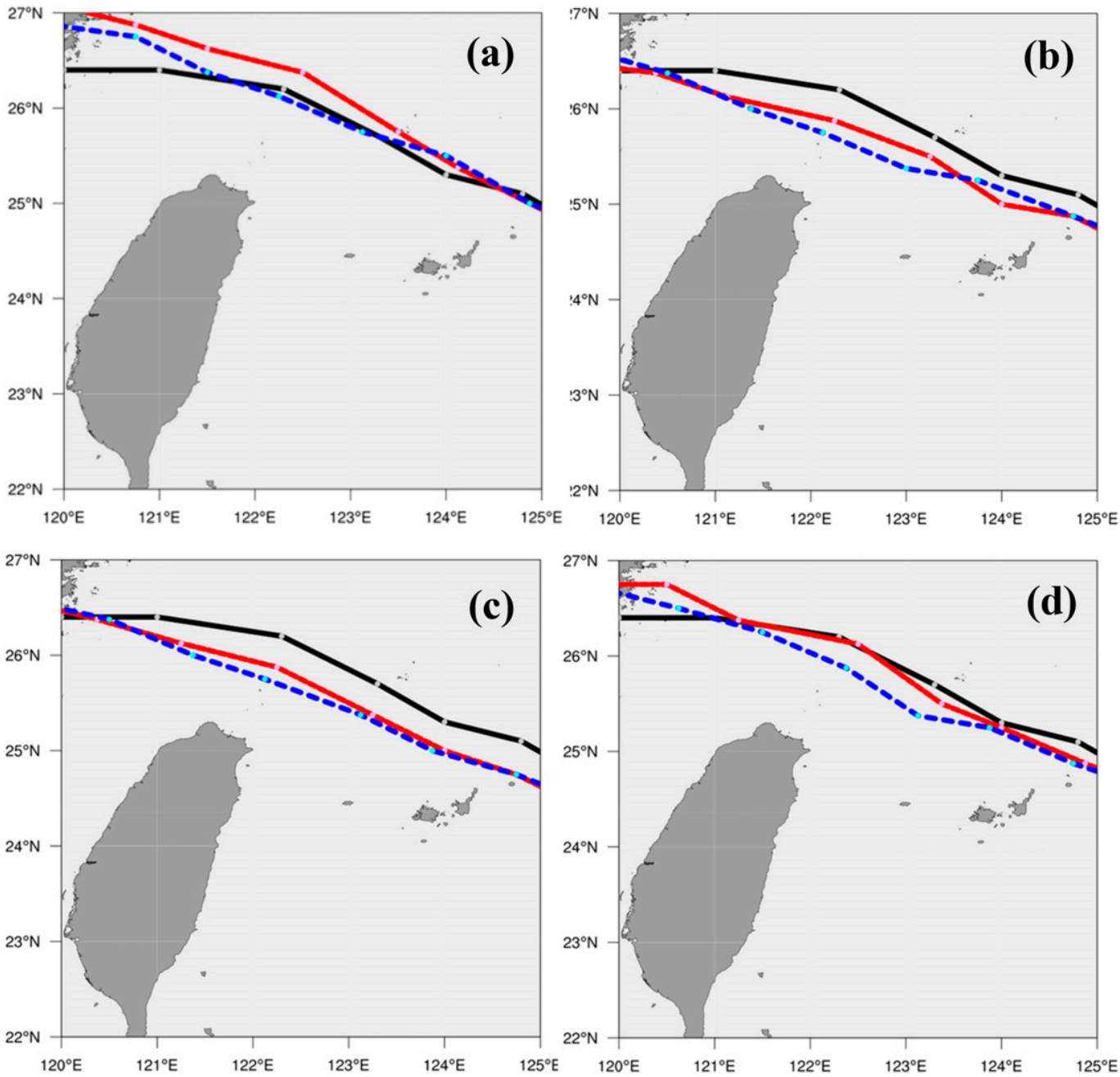

FIG. 5. Simulated tracks for Maria (2018) for (a) CTL but with cloud microphysics scheme changed to WSM6; (b) as CTL, but with cloud microphysics scheme changed to the Thompson scheme; (c) as CTL, but with 2010 shallow convection scheme; and (d) as CTL, but with 2010 shallow convection scheme and 2010 deep convection scheme. The simulated tracks are in red with Taiwan terrain and in dashed blue without Taiwan terrain, and the JMA best track is in black. All the three tracks are at an interval of $3 \mathrm{~h}$.

more asymmetric at $39 \mathrm{~h}$ with stronger updrafts at the southeast quadrant of the inner vortex (Fig. 6d) in response to the strong convergence, supported by the observed radar reflectivity ( $\mathrm{dBZ}$ ) except for that stronger echoes are also produced near offshore of northeastern Taiwan (figures not shown). Upward motions have also been produced along the northwestern slope of the CMR at $36 \mathrm{~h}$ and become stronger at $39 \mathrm{~h}$ as the inner vortex core is closer and provides more intense northerly wind directly impinging on the mountain. The simulated rainfall produced by the updrafts is similar to the observed rainfall, but with a somewhat underpredicted maximum (250 versus $334 \mathrm{~mm}$ ) near the northern CMR and a less southward extension of the intense rainfall (figures not shown).

\section{e. Mean transverse typhoon circulation}

As the typhoon is approaching Taiwan terrain, the typhoon circulation at lower levels is being modified by the topographic effects of the terrain. Figure 7 shows azimuthal-mean vertical circulation across the typhoon center for radial-vertical wind and tangential wind speed at 36 and $39 \mathrm{~h}$ to understand the structural changes of the typhoon vortex as the track deflection is taking place. The simulated typhoon at $36 \mathrm{~h}$ exhibits common features of an intense typhoon with strong radial inflow outside the radius of about $0.6^{\circ}$ and below $2-\mathrm{km}$ height as well as intense outflow above $10-\mathrm{km}$ height with the strongest outflow near 14-km height (Fig. 7a). The radius of maximum tangential wind (RMW) increases outward with height in association with stronger upward motions outside the RMW and above about 4-km height (Fig. 7c). Beyond the radius of about $2^{\circ}$, weak downward motions are induced from the upper-level outer outflow layer. At $39 \mathrm{~h}$, the maximum-wind speed core $\left(50-55 \mathrm{~m} \mathrm{~s}^{-1}\right)$ penetrates inward and develops slightly higher and farther outward below about $6-\mathrm{km}$ height than at $36 \mathrm{~h}$ (Fig. 7b). The azimuthal-mean vertical motions are considerably 

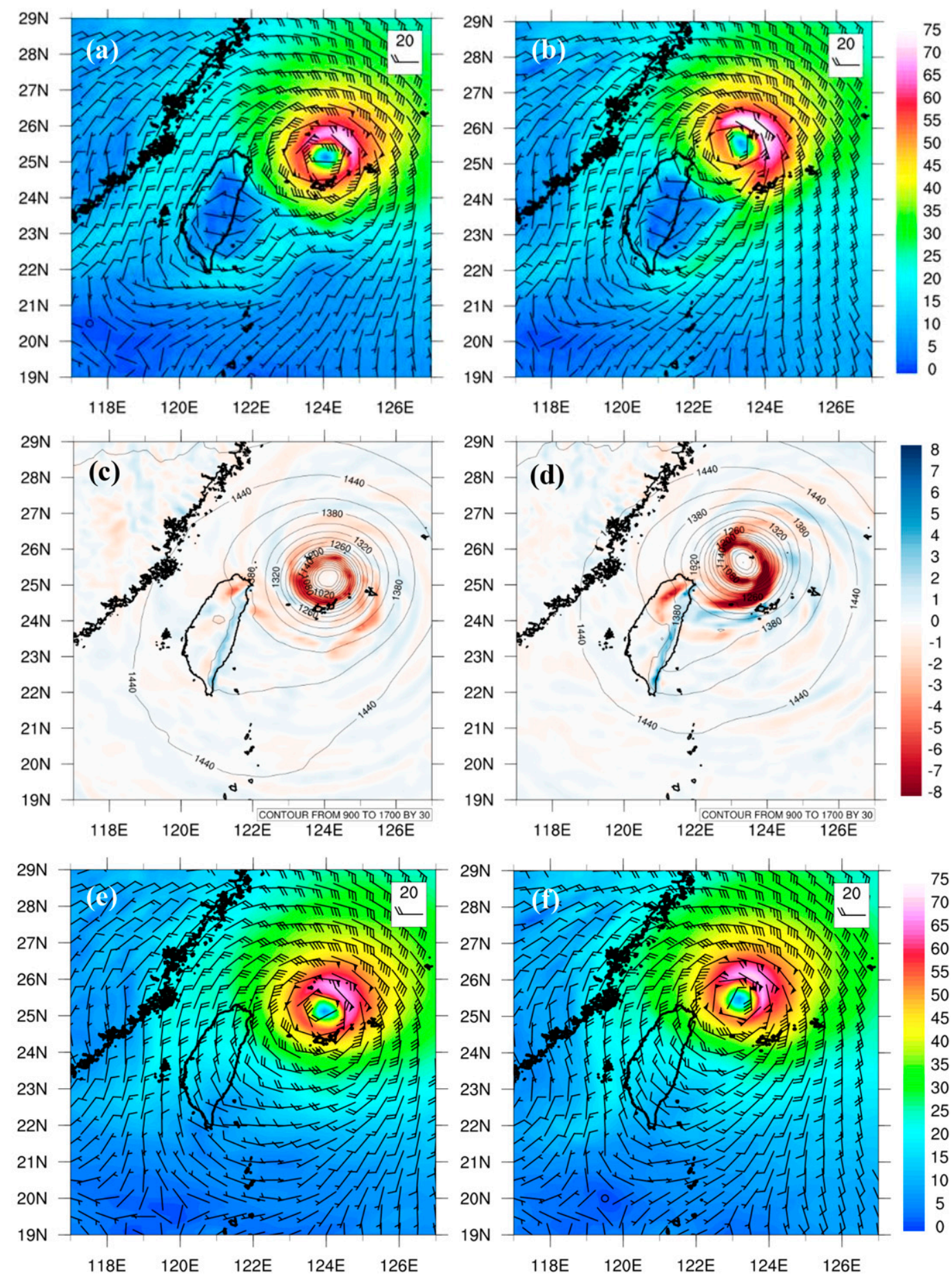

FIG. 6. Simulated wind barbs $\left(\mathrm{m} \mathrm{s}^{-1}\right)$ and wind speed (shaded colors; $\mathrm{m} \mathrm{s}^{-1}$ ) for CTL at $850 \mathrm{hPa}$ at (a) 36 and (b) 39 h. (c), (d) Vertical velocity (omega) $\left(\mathrm{Pa} \mathrm{s}^{-1} \sim 0.1 \mathrm{~m} \mathrm{~s}^{-1}\right.$ ) (shaded colors; $\mathrm{m} \mathrm{s}^{-1}$ ) and geopotential height (gpm; contours at interval of $30 \mathrm{gpm}$ ) at 36 and $39 \mathrm{~h}$, respectively. (e),(f) As in (a) and (b), respectively, but for noT.

stronger in the eyewall associated with moderately stronger inflow below 2-km height, significantly stronger outflow in about 4-10-km height and slightly stronger outflow above about $12-\mathrm{km}$ height (Fig. 7d). The upper-level outer outflow is slightly stronger than at $36 \mathrm{~h}$. The downward motions from the outer outflow at larger radii are more pronounced over the radius of $2^{\circ}$ at $39 \mathrm{~h}$. Thus, the mean transverse circulation becomes stronger as the typhoon is closer offshore of northern Taiwan. On the 

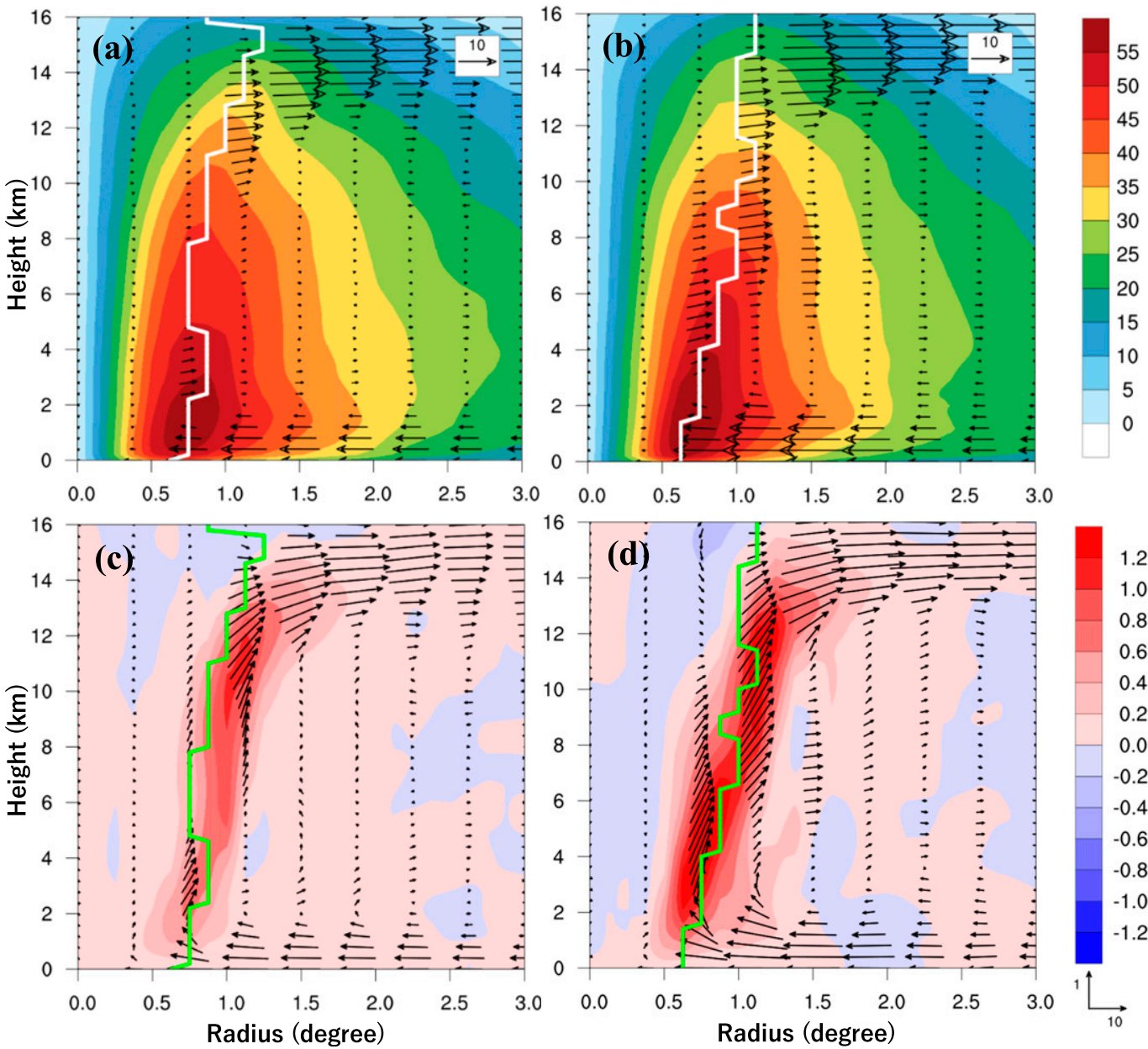

FIG. 7. Azimuthal-mean vertical circulation across the typhoon center for radial-vertical wind (vectors; $\mathrm{m} \mathrm{s}^{-1}$ ) and tangential wind speed (shaded colors; $\mathrm{m} \mathrm{s}^{-1}$ ) for CTL at (a) 36 and (b) $39 \mathrm{~h}$. (c), (d) As in (a) and (b), but for vertical velocity (shaded colors; $\mathrm{m} \mathrm{s}^{-1}$ ), respectively, and the radial and vertical wind scales $\left(\mathrm{m} \mathrm{s}^{-1}\right)$ are indicated at the lower right in (d). The vertical component of the wind in (a) and (b) is amplified by 10 times in (c) and (d). Connected white line and green line segments indicate the radius of maximum tangential wind speed in the top and bottom panels, respectively.

other hand, the mean transverse circulation for noT (not shown) at $39 \mathrm{~h}$ is quite similar to that at $36 \mathrm{~h}$, which is also similar to that for CTL at $36 \mathrm{~h}$ (prior to the track deflection).

\section{Dynamic analyses}

In this section, several interesting relevant aspects are discussed in regard to the evolving features of the typhoon near the track deflection and the sensitivity of the typhoon track to Taiwan terrain height.

\section{a. Angular momentum budget}

To explore the evolution of AM associated with the typhoon near the track deflection, Fig. 8 shows the azimuthal-mean radial-vertical wind across the typhoon center and AM at 36, 39 , and $40 \mathrm{~h}$ as well as the time change rate of mean AM at $39 \mathrm{~h}$ for CTL. The results may illustrate the dynamic processes for $\mathrm{CTL}$ in the presence of the terrain. At $36 \mathrm{~h}$, mean AM decreases inward and upward and exhibits approximately constant values along the eyewall (Fig. 8a). Contours of AM slope outward and flatten in the upper outflow layer as shown in various intense hurricanes over the ocean (e.g., Zhang et al. 2001). Associated with the strengthened outflow from the eyewall at about 4-10-km height, AM at $39 \mathrm{~h}$ is slightly weaker outside of the RMW than at $36 \mathrm{~h}$. In the outer inflow layer at low levels below 2-3-km height, AM is weaker than at $36 \mathrm{~h}$ due to the reduced tangential wind component south of the vortex center and east of Taiwan. The mean AM in the tropospheric outflow region is decreasing with time in association with an outward decaying of its magnitude. The differences between the mean $\mathrm{AM}$ at 39 and $40 \mathrm{~h}$ indicate the actual local time change rate of AM, which is associated with an increase in 2-4-km height and a decrease in $6-12-\mathrm{km}$ height near the radius of maximum tangential wind and in the tropospheric outflow region outside the eyewall as well as a larger maximum decrease in the region of the low-level inflow near the 

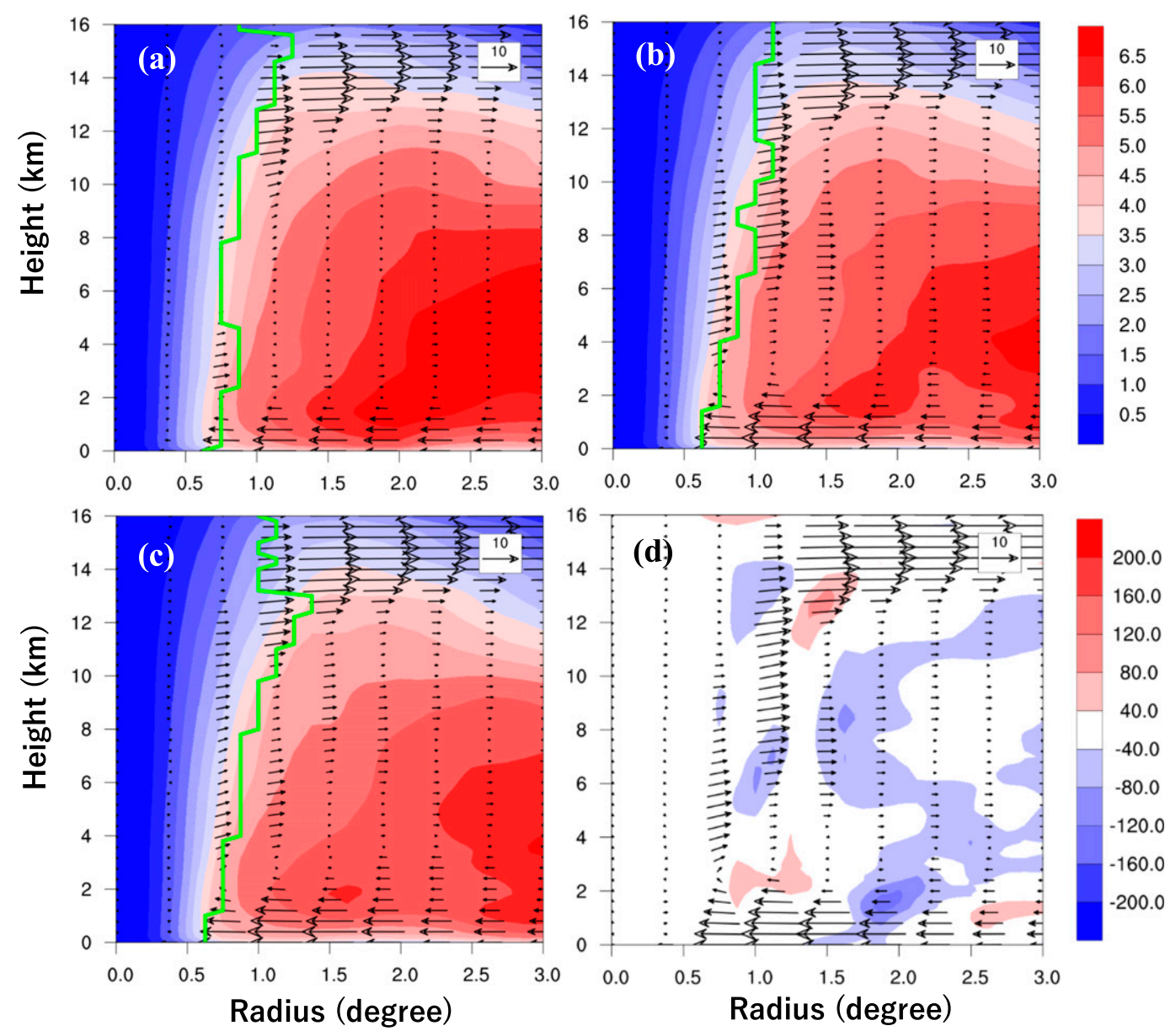

FIG. 8. Vertical cross section across the typhoon center for CTL for azimuthal-mean radial-vertical wind (vector in $\mathrm{m} \mathrm{s}^{-1}$ ) and angular momentum (AM) (shaded colors; $10^{6} \times \mathrm{m}^{2} \mathrm{~s}^{-1}$ ) at (a) 36, (b) 39, and (c) $40 \mathrm{~h}$. (d) As in (c), but for the time change rate of mean AM (shaded colors; $\mathrm{m}^{2} \mathrm{~s}^{-2}$ ) at $39 \mathrm{~h}$. Connected green line segments in (a)-(c) indicate the radius of maximum tangential wind speed.

radius of $1.9^{\circ}$ (Fig. 8d). Calculation using the mean AM at 38 and $40 \mathrm{~h}$ also shows qualitatively similar patterns (not shown).

We conducted the decomposition of AM into a symmetric part (azimuthal mean) and an eddy part (the deviation from the mean) for diagnosing the AM budget (see the appendix). Figure 9 shows the vertical cross section across the typhoon center for the azimuthal-mean radial-vertical wind and AM budget terms at $36 \mathrm{~h}$. Radial mean AM advection gives positive contribution to AM in the low-level inflow region inside the radius of $2^{\circ}$ and upper-level outflow region outside the radius of $1.5^{\circ}$, while producing larger negative AM tendency in the eyewall (Fig. 9a). Note that there is a large negative zone in radii of $2^{\circ}-2.5^{\circ}$ below $1.5-\mathrm{km}$ height, which is induced by the weaker AM outside the radius of about $2^{\circ}$ (see Fig. 8a). Vertical mean AM advection tends to offset radial mean AM advection, except for the upper-level outer outflow region outside the radius of $1.5^{\circ}$ (Fig. 9b). Radial eddy AM advection is positive in the eyewall but mainly inside the RMW and provides weak negative contribution at low levels outside the radius of $2^{\circ}$ (Fig. 9c). Vertical eddy AM advection is relatively minor with some weak positive production below the midlevel eyewall and negative production in the upper-level outflow layer (Fig. 9d). Coriolis torque contributes large positive and negative AM generation rates in response to the strong lowlevel inflow and upper-level outflow, respectively (Fig. 9e). The net AM budget, as a sum of all the budget terms (excluding the turbulent diffusion term), exhibits positive AM generation rate in the low-level inflow region inside the radius of $2^{\circ}$ with upward extension mainly outside the RMW along the outer edge of the eyewall (Fig. 9f). Above 11-km height, AM is at a loss with negative tendency in the outflow layer. AM is also weakened near the radius of $2^{\circ}$ below about $3-\mathrm{km}$ height, reflecting the topographic effects of Taiwan terrain on weakening the tangential wind component. Note that the diffusive tendency at low levels due to the turbulent term can be large so that the large AM generation may be greatly reduced.

In response to the increased topographic effects at $39 \mathrm{~h}$, the contributions from the AM budget terms are largely modified as shown in Fig. 10. It appears that both radial and vertical mean AM advections at this time are stronger and 

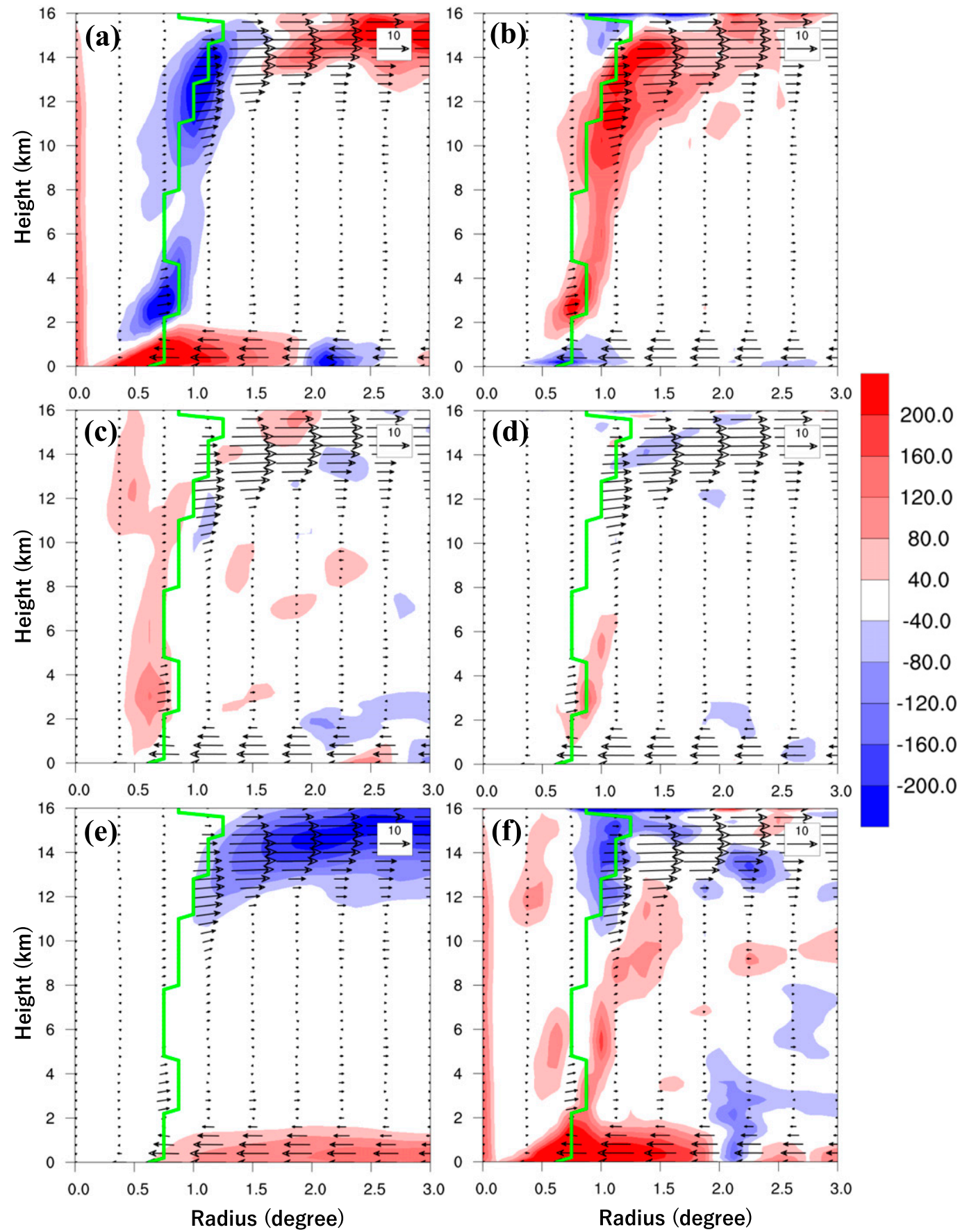

FIG. 9. Vertical cross section across the typhoon center for CTL at $36 \mathrm{~h}$ for azimuthal-mean radial wind (vectors; $\mathrm{m} \mathrm{s}^{-1}$ ) and angular momentum (AM) budget terms (shaded colors; $\mathrm{m}^{2} \mathrm{~s}^{-2}$ ): (a) radial mean AM advection, (b) vertical mean AM advection, (c) radial eddy AM advection, (d) vertical eddy AM advection, (e) AM generation rate by Coriolis force, and (f) the AM budget sum. Connected green line segments indicate the radius of maximum tangential wind speed.

are associated with large negative and positive AM productions in the eyewall updraft, respectively (Figs. 10a,b). Radial eddy AM advection now contributes larger negative AM production in the low-level inflow layer outside the radius of $1^{\circ}$ below 3-4-km height (Fig. 10c). Vertical eddy AM advection induces positive AM tendency in the midlevel eyewall above which negative production is prominent up to $16-\mathrm{km}$ height (Fig. 10d). At 39 h, Coriolis torque gives similar AM generation except for positive contribution in the deeper inflow layer and some negative contribution in the outflow region of 

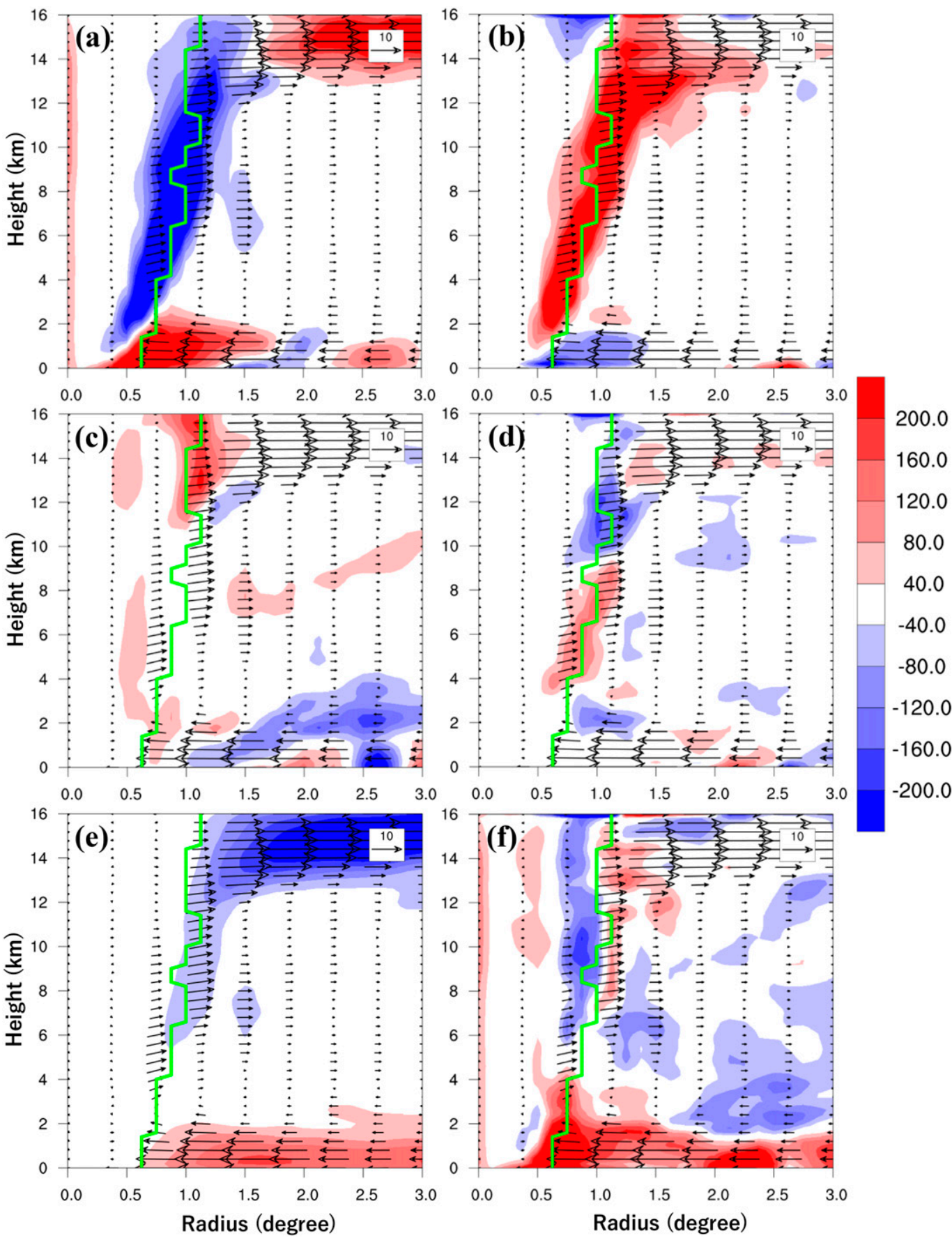

FIG. 10. As in Fig. 9, but at $39 \mathrm{~h}$.

about 6-11-km height along the outer eyewall (Fig. 10e). Consequently, the positive AM budget sum is largely produced in the region of low-level inflow layer over which noted negative AM production is widely distributed from the eyewall to the outer region over the radius of $3^{\circ}$ (Fig. 10f). Thus, the larger positive AM budget in the low-level eyewall is supported mainly from the radial mean AM advection that causes an intensification of the inner typhoon circulation at lower levels after $36 \mathrm{~h}$ as seen in Fig. 4c. On average, the outer typhoon circulation above the low-level inflow layer at $39 \mathrm{~h}$ will be weakened due to the enhanced negative radial eddy AM advection with the largely reduced tangential wind farther east of Taiwan terrain and south of the vortex center. Note that the differences between the net AM budget (Fig. 10f) and the actual time change rate of AM (Fig. 8d) indicate the budget residual that is accounted for by turbulent 


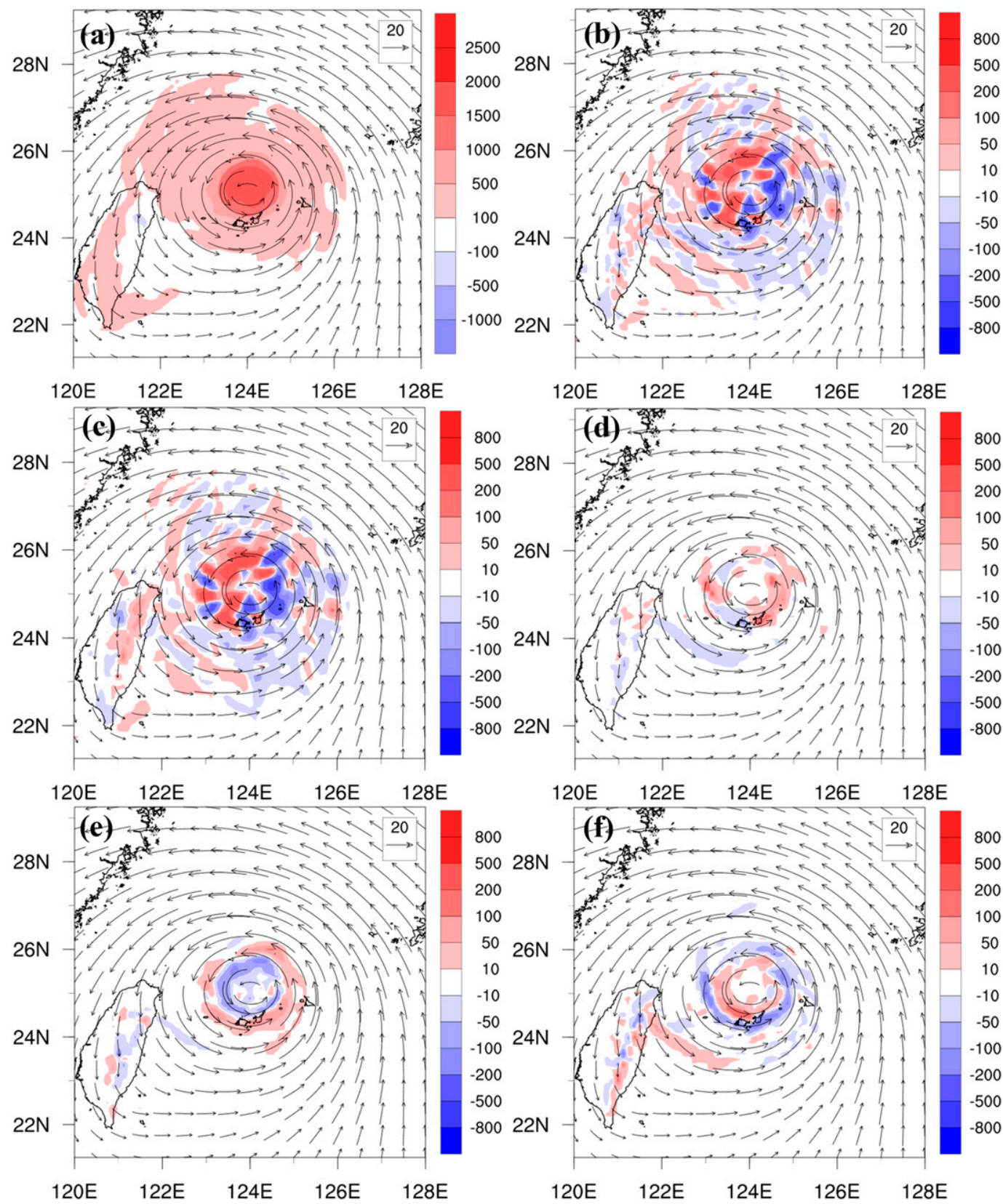

FIG. 11. Simulated vorticity and budget terms averaged from 1- to 8-km height for CTL at $36 \mathrm{~h}$ for (a) vorticity (shaded colors; $10^{-6} \mathrm{~s}^{-1}$ ), and (b) sum of vorticity budget terms, (c) horizontal advection, (d) vertical advection, (e) stretching, and (f) tilting, all in $10^{-9} \mathrm{~s}^{-2}$. The budget sum includes all the budget terms including the solenoidal term. The horizontal wind vectors $\left(\mathrm{m} \mathrm{s}^{-1}\right)$ averaged from 1- to 8-km height are overlaid.

diffusion as well as the model-inherent numerical smoothing. Above the boundary layer, the AM budget analysis appears to somewhat overestimate the actual AM tendency, in particular, a larger decrease in the upper eyewall above 6-km height.

\section{b. Vorticity budget}

A vorticity budget is analyzed to identify the relative importance of different physical processes causing the track deflection. Figure 11 shows the vertical vorticity and its budget terms averaged from $1-$ to $8-\mathrm{km}$ height at $36 \mathrm{~h}$. The major typhoon circulation possesses quite symmetric positive vorticity within a radius of about $1.5^{\circ}$ from the center. It is observed that positive vorticity is also produced along the western slope of the CMR and at the lee side of southern Taiwan with an offshore extension (Fig. 11a). Horizontal vorticity advection gives significant vorticity changes (Fig. 11c) and contributes to a major source of positive local vorticity tendency, represented 

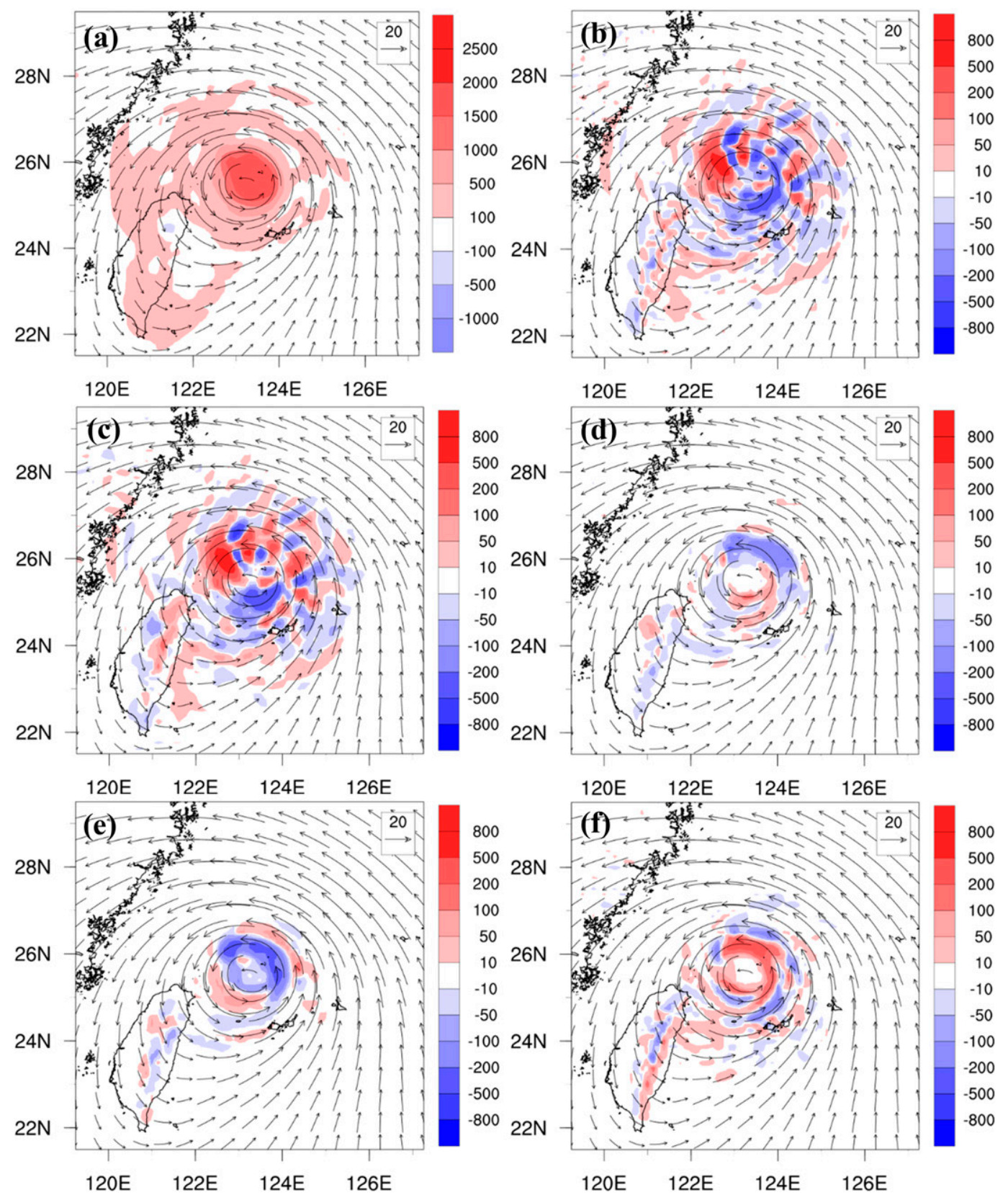

FIG. 12. As in Fig. 11, but at $39 \mathrm{~h}$.

by the sum of all budget terms in the vorticity equation except for the turbulent diffusion term (see Huang et al. 2017) (Fig. 11b). Indeed, the larger positive vorticity budget sum is present at the west-northwestward flank of the inner vortex under the environmental steering condition. Vertical vorticity advection gives some positive contribution at the eastern flank of the inner vortex (Fig. 11d). Vorticity stretching tends to counteract with vorticity tilting and produces positive and negative tendency concentrated in the outer and inner annuli of the vortex core, respectively. At this time, some positive vorticity generation from vorticity tilting is also found eastward offshore from Taiwan terrain.
Figure 12 shows the vertical vorticity and its budget terms averaged from 1 - to $8-\mathrm{km}$ height at $39 \mathrm{~h}$. On average, the positive vorticity of the inner vortex core remains rather symmetric, while less organized in the outer region than at $36 \mathrm{~h}$ (Fig. 12a). Noted positive vorticity is produced at $39 \mathrm{~h}$ from offshore north of Taiwan down to the southern end of the CMR with a northeastward extension toward the inner vortex. Horizontal vorticity advection continues to dominate the total vorticity budget (Fig. 12b), with the larger positive contribution at the northwest quadrant of the inner vortex (Fig. 12c). Some positive vorticity generation is induced at the southern flank of the vortex core by vertical 
vorticity advection (Fig. 12d). Vorticity stretching and vorticity tilting remain roughly counteracting with each other (Figs. 12e,f) and give larger contributions in the vortex core. It appears that larger negative vorticity stretching is induced at the northeastern flank of the vortex core, physically leading to a driving direction of the vortex toward the southwest.

\section{c. Vortex translation}

The vorticity budget terms were decomposed into the symmetric part and $\mathrm{WN}-1$ component to understand the relative importance of different physical terms in driving the vortex. The geometric features of WN-1 vorticity budget closely follow the total undecomposed field (figures omitted herein), which are similar to those shown in Huang et al. (2017). The regression method can be applied to quantify the contribution of each term included in the vorticity budget. Figure 13 shows the vortex translation velocity $\left(\mathrm{m} \mathrm{s}^{-1}\right)$ as estimated by the WN-1 decomposition of vorticity budget terms averaged from 1 - to $8-\mathrm{km}$ height at different times for CTL and noT. The regressed vortex movement agrees well with the actual vortex movement of the model simulation (computed using the vortex track positions), except with slight deviations for the moving speed. At $36 \mathrm{~h}$, the regressed vortex translation at a speed of $7.6 \mathrm{~m} \mathrm{~s}^{-1}$ is dominated by horizontal vorticity advection and is westnorthwestward closely following the total (net) translation. The other three budget terms appear to be much smaller, with the largest southeastward translation at a speed of $1.22 \mathrm{~m} \mathrm{~s}^{-1}$ induced by the stretching term. At $38 \mathrm{~h}$, horizontal vorticity advection continues to dominate the total budget and induces a translation that is increased to $11 \mathrm{~m} \mathrm{~s}^{-1}$, but at an increased separation angle from the net translation toward west-northwest at a speed of $8.81 \mathrm{~m} \mathrm{~s}^{-1}$. The separation angle and translation speed induced by horizontal vorticity advection further increase with a larger northward component at $39 \mathrm{~h}$. The northward component of the translation induced by horizontal vorticity advection is somewhat offset by the southward component from vertical vorticity advection with an induced translation speed of $2.63 \mathrm{~m} \mathrm{~s}^{-1}$ and vorticity stretching with an induced translation speed of $4.77 \mathrm{~m} \mathrm{~s}^{-1}$. Vorticity tilting with an induced translation speed of $3.04 \mathrm{~m} \mathrm{~s}^{-1}$ is pointing primarily toward north. At $44 \mathrm{~h}$ when the track deflection is near completion, the separation angle between the directions of translation induced by the net budget and horizontal advection is largely reduced to about $10^{\circ}$, mainly due to the primarily southward contribution from vorticity stretching with an induced translation speed of $2.98 \mathrm{~m} \mathrm{~s}^{-1}$. The total translation at the later deflection stage is accelerating at a faster speed of $12.09 \mathrm{~m} \mathrm{~s}^{-1}$ (compared to $7.6 \mathrm{~m} \mathrm{~s}^{-1}$ at $36 \mathrm{~h}$ ), which can also be found in the actual vortex motion vector. In response to the increased westward translation from horizontal advection and southward translation from vorticity stretching, the vortex is driven more westward and less northward near the completion of track deflection. During the track deflection period, the horizontal vorticity advection is always more important than the other terms, which is in agreement with the dominant PV horizontal advection in the
PV budget analysis for idealized westward cyclones past a mountain (e.g., Huang and Wu 2018). The horizontal flow change is more responsible for the vortex movement, while other effects (such as vertical transport and diabatic heating) can moderately modulate the track to some extent.

\section{d. Terrain effects}

The track deflection of the simulated Maria is shown to be related to the topographic influence of Taiwan terrain in Fig. 13. Removal of Taiwan terrain in noT has resulted in a relief of the track deflection near offshore of northern Taiwan. By comparing the induced translation from different vorticity budget terms between CTL and noT in Fig. 13, it can be found that the reduced northward translation in the absence of Taiwan terrain results from the less northward translation that is essentially dominated by horizontal vorticity advection. As the track deflection is taking place, the other three budget terms in noT are also at smaller magnitudes than in CTL. The increased northward translation induced by horizontal vorticity advection can be attributed to changes in the typhoon circulation when approaching northern Taiwan.

To further analyze the response of the typhoon movement to flow changes, Fig. 14 shows the WN-1 asymmetric flow averaged from 1- to $4-\mathrm{km}$ height at $39 \mathrm{~h}$ for CTL and noT. The actual typhoon movement before the track deflection closely follows the WN-1 flow east of $124^{\circ} \mathrm{E}$ for both CTL and noT (Figs. 14a,b). In the presence of Taiwan terrain, the WN-1 flow is stronger east of Taiwan and in the vicinity of the vortex core (Fig. 14a). This will facilitate stronger split flow around the mountain toward the vortex core as indicated by their differences at $39 \mathrm{~h}$ (Fig. 14c). Consequently, the vortex core is associated with stronger WN-1 northwestward wind compared to weaker WN-1westnorthwestward wind in the absence of Taiwan terrain (Fig. 14b). As the typhoon is resuming to the original translating direction, their differences in the WN-1 flow become more westward in the vicinity of the vortex (Fig. 14d). Note that we have used the WN-1 flow at $44 \mathrm{~h}$ for CTL and at $45 \mathrm{~h}$ for noT to compute the flow differences since their vortex centers are collocated more closely. Use of the WN-1 flow either at 44 or $45 \mathrm{~h}$ for CTL and noT provides similar flow patterns.

For further understanding the influence of Taiwan terrain on the evolving typhoon in a longer period, Fig. 15 shows Hovmöller plots from 24 to $48 \mathrm{~h}$ with respect to temporal and radial variations of radial and tangential wind speeds at $1-\mathrm{km}$ height and vertical velocity averaged from $3-$ to $12-\mathrm{km}$ height, both averaged from radii of $0.625^{\circ}$ to $0.875^{\circ}$ (the eyewall region). The radial and tangential wind velocities are computed without removing the translation speed of the vortex. For CTL, inward radial wind at $1-\mathrm{km}$ height becomes much stronger at the southeast quadrant as the track deflection is taking place from $36 \mathrm{~h}$, with stronger upward motions at the southern flank (Fig. 15a). Stronger downward motions at the northwest quadrant are weakened at $1-\mathrm{km}$ height in the absence of Taiwan terrain after about $41 \mathrm{~h}$ (Fig. 15b). The larger difference in radial wind is also 

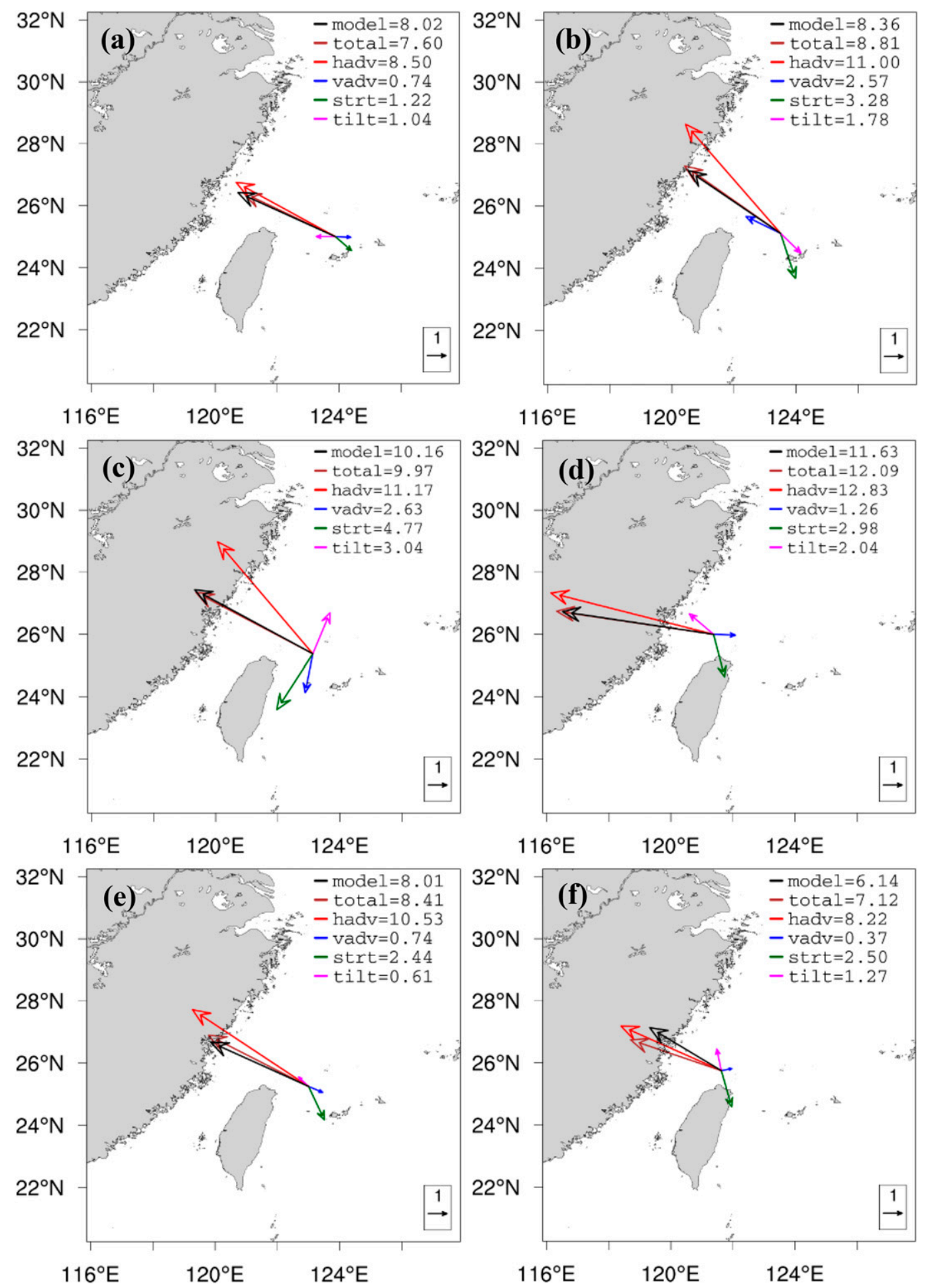

FIG. 13. Vortex translation velocity $\left(\mathrm{m} \mathrm{s}^{-1}\right)$ regressed by wavenumber-1 decomposition of vorticity budget terms averaged from 1- to 8-km height for CTL at (a) 36, (b) 38, (c) 39, and (d) $44 \mathrm{~h}$, and for noT at (e) 39 and (f) $44 \mathrm{~h}$. In each panel, arrows indicate the actual motion of the model simulation (black), the total budget sum (brown), horizontal advection (red), vertical advection (blue), stretching (green), and tilting (magenta), with their individual amounts given at the top right of each panel. 

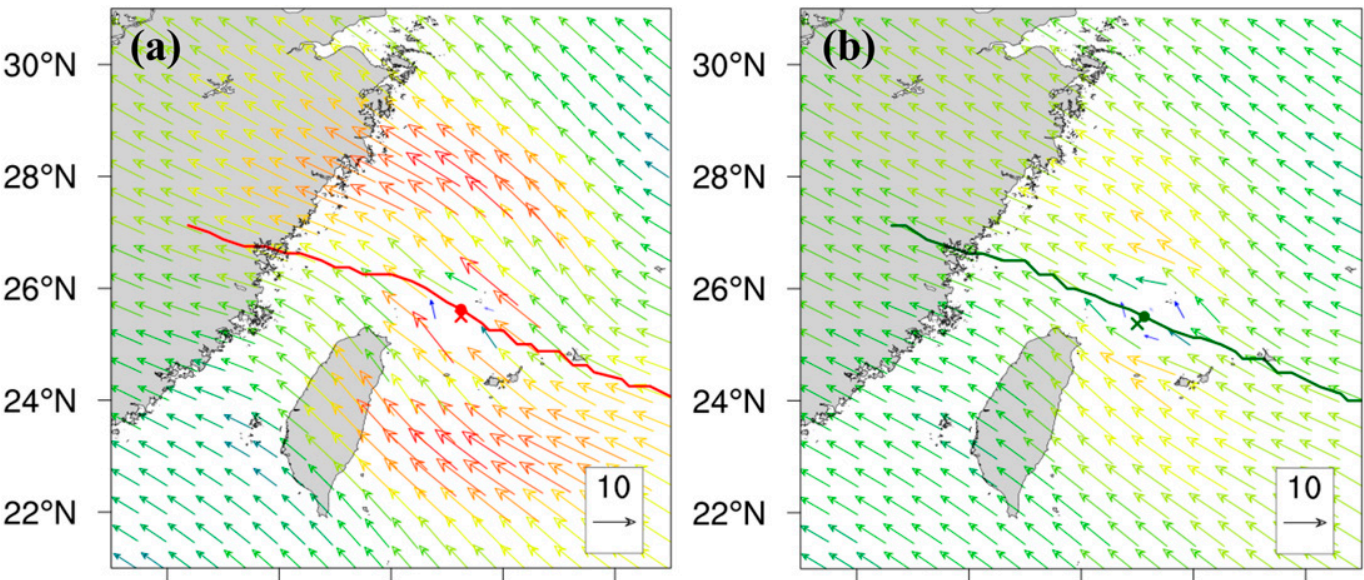

$118^{\circ} \mathrm{E} 120^{\circ} \mathrm{E} 122^{\circ} \mathrm{E} 124^{\circ} \mathrm{E} 126^{\circ} \mathrm{E}$

$118^{\circ} \mathrm{E} 120^{\circ} \mathrm{E} 122^{\circ} \mathrm{E} 124^{\circ} \mathrm{E} 126^{\circ} \mathrm{E}$
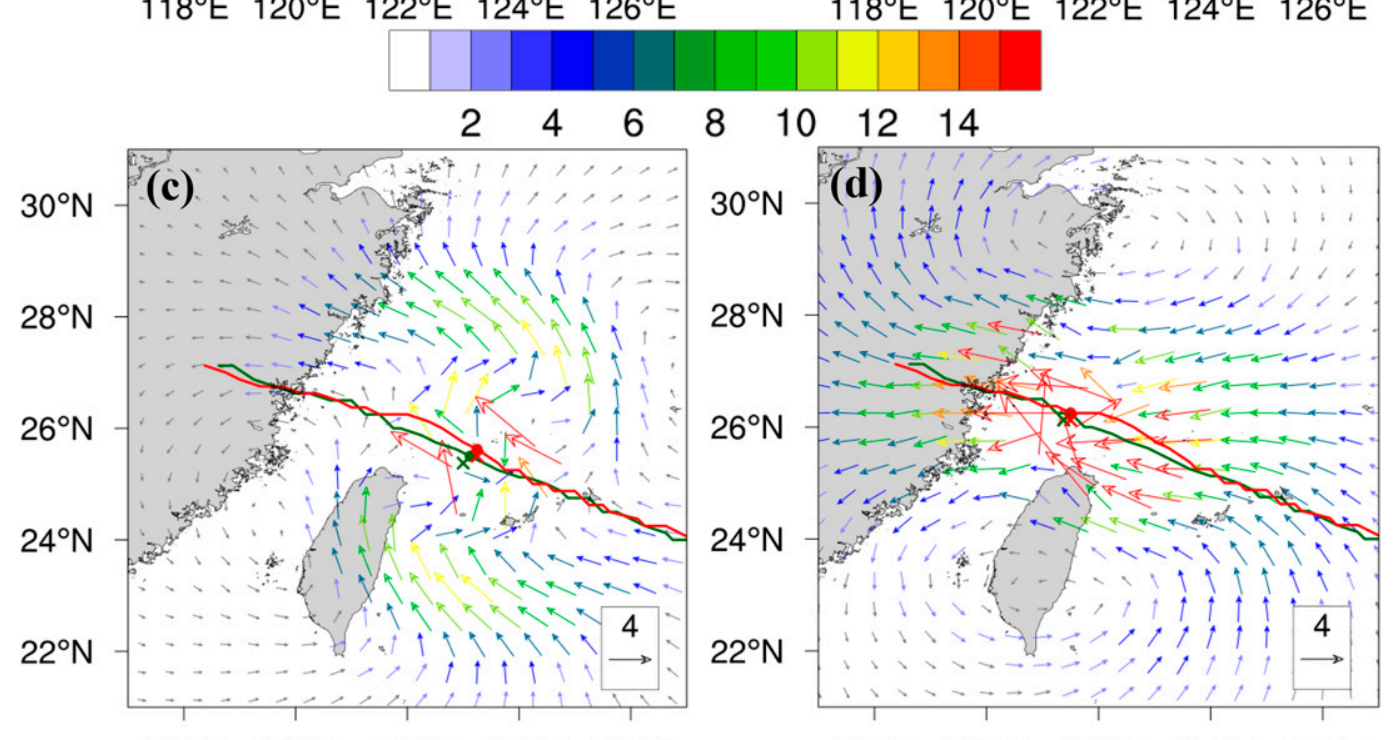

$118^{\circ} \mathrm{E} 120^{\circ} \mathrm{E} 122^{\circ} \mathrm{E} 124^{\circ} \mathrm{E} 126^{\circ} \mathrm{E}$

$118^{\circ} \mathrm{E} 120^{\circ} \mathrm{E} 122^{\circ} \mathrm{E} 124^{\circ} \mathrm{E} 126^{\circ} \mathrm{E}$

\section{$\begin{array}{llllllll}1.5 & 2 & 2.5 & 3 & 3.5 & 4 & 4.5 & 5\end{array}$}

FIG. 14. (a) The wavenumber-1 asymmetric flow (with wind speed; $\mathrm{m} \mathrm{s}^{-1}$, indicated by colors) averaged from 1 - to 4-km height at $39 \mathrm{~h}$ for CTL. (b) As in (a), but for noT. (c) The difference in the asymmetric flow between CTL and noT at $39 \mathrm{~h}$. (d) As in (c), but for the difference between CTL at $44 \mathrm{~h}$ and noT at $45 \mathrm{~h}$. Solid point and cross sign represent the typhoon centers defined by the locations of minimum surface pressure and lowest wind speed, respectively, in red for CTL and in green for noT.

induced after $45 \mathrm{~h}$ as the typhoon moves closer to mainland China. In response to the increased inward radial wind near the deflection time, tangential wind and upward motions for CTL are stronger at the northeast quadrant but with about a 1-h delay (Fig. 15c). The position of maximum upward motion for CTL is about one-half quadrant upwind of the position of maximum tangential wind, while they are in phase for noT (Fig. 15d). The tangential wind for CTL is weakened at the southern flank after about $42 \mathrm{~h}$ and is weaker than for noT. As evident in Fig. 6, the inner vortex core after $39 \mathrm{~h}$ has been greatly influenced by the strong radial inflow (mainly southerly) to the southeast of the vortex center in the presence of Taiwan terrain, with the intensified tangential wind to the northeast and upwind stronger vertical motions. Upstream influence of Taiwan terrain on the approaching typhoon indeed has occurred earlier before $24 \mathrm{~h}$ (not shown in the figure), but is not prominent until $36 \mathrm{~h}$ near the commencement of the track deflection as evident in Fig. 15.

\section{e. Sensitivity on terrain height}

Presentations at earlier sections have revealed the effects of Taiwan terrain on the track deflection of Maria approaching near offshore of northern Taiwan. Several sensitivity experiments, 

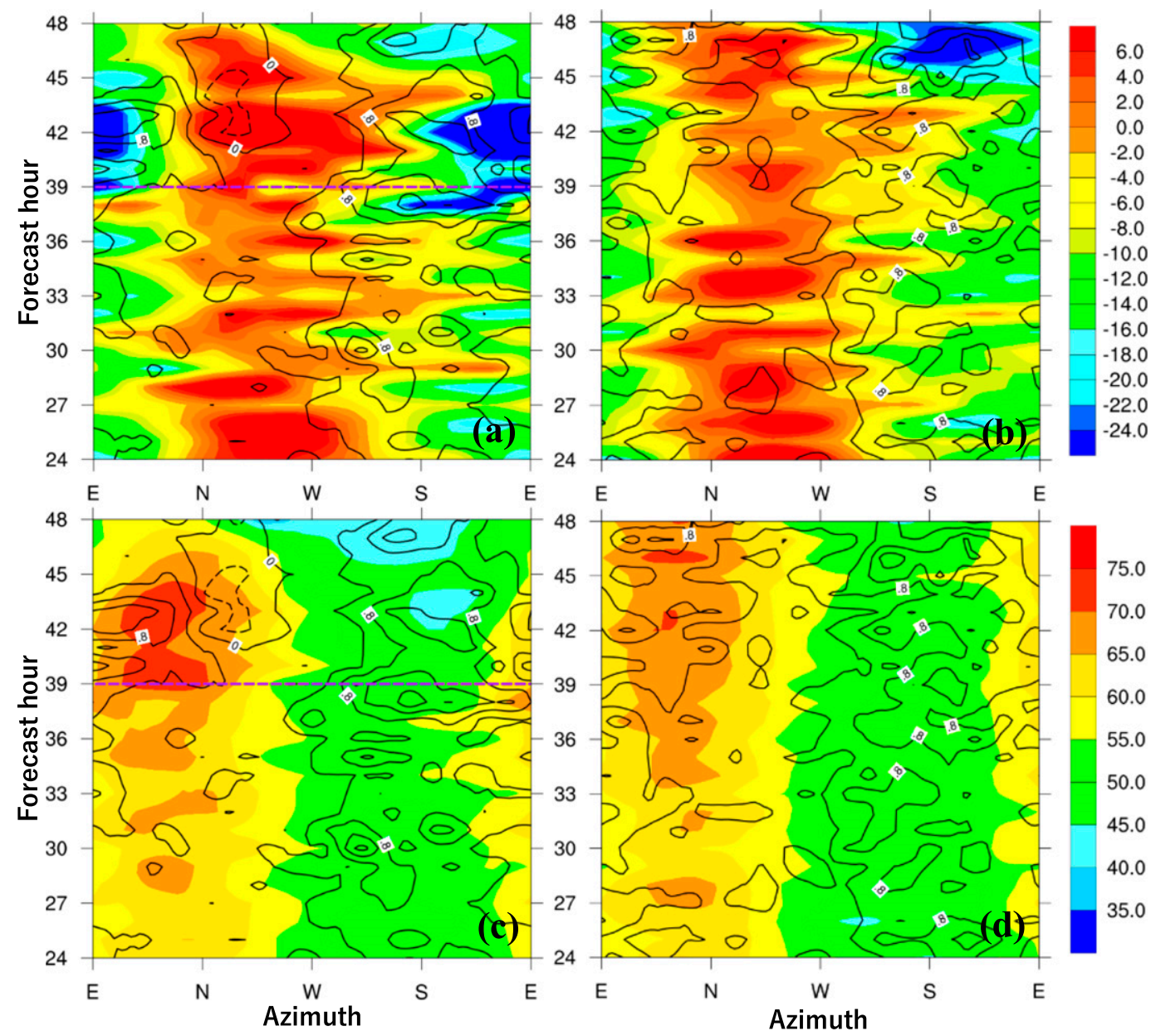

FIG. 15. (a) Hovmöller plot of 24-48-h radial wind speed (shaded colors; $\mathrm{m} \mathrm{s}^{-1}$ ) at 1-km height and vertical velocity (contours at interval of $0.4 \mathrm{~m} \mathrm{~s}^{-1}$ ) averaged from 3- to $12-\mathrm{km}$ height, both averaged from radii of $0.625^{\circ}$ to $0.875^{\circ}$ with respect to azimuth for (a) CTL. (b) As in (a), but for noT. (c),(d) As in (a) and (d), respectively, but for tangential wind. The purple dashed line in (a) and (c) indicates the time of track deflection in CTL.

H0, H50, and H130, were conducted to realize whether changing Taiwan terrain height will affect the typhoon track. As seen in Fig. 16, an increase in Taiwan terrain height by $30 \%$ in $\mathrm{H} 130$ only results in a small northward deviation from that with the normal height in CTL, while $50 \%$ and $100 \%$ reductions of the terrain height still give some northward (or rightward) deviations from noT. The contrast of land and sea thus is also complementary to the track deflection by cutting off the water vapor supply over the island. In contrast, for westward cyclones approaching the central peak of the mountain range, previous studies have found that the track deflection near landfall will be greatly enhanced as the mountain height is increased by 50\% (e.g., Huang et al. 2016; Huang and Wu 2018). Since the track deflection of Maria occurs near offshore of northern Taiwan in response to the developing southerly flow east of Taiwan, the recirculating flow around the southern mountain corner in the presence of a higher mountain may not be intensified to have a greater impact on the inner vortex circulation. We will utilize an idealized mesoscale model to identify the sensitivity of track deflection to the cyclone's initial intensity and size, as well as meridional departure distance relative to the mountain range.

\section{Results of idealized experiments}

\section{a. The numerical model}

For idealized experiments in this study, we used the WRF model version 3.4.1 (http://wrf-model.org/index.php; Skamarock et al. 2008), which is nonhydrostatic in terrain-following coordinates. Two nested grid meshes are employed with the same 41 vertically stretched layers topped at $20-\mathrm{km}$ height. The model simulations include the Yonsei University (YSU) PBL parameterization, the WRF single-moment 6-class graupel cloud microphysics (WSM6) and the modified Tiedtke cumulus parameterization (for references, see Huang et al. 2016). The simulations have not included radiative effects since the track deviation is mainly concerned near the topography at a relatively short time scale.

For consistency with the real case of Maria, all the idealized simulations conducted in this study are considered on a 


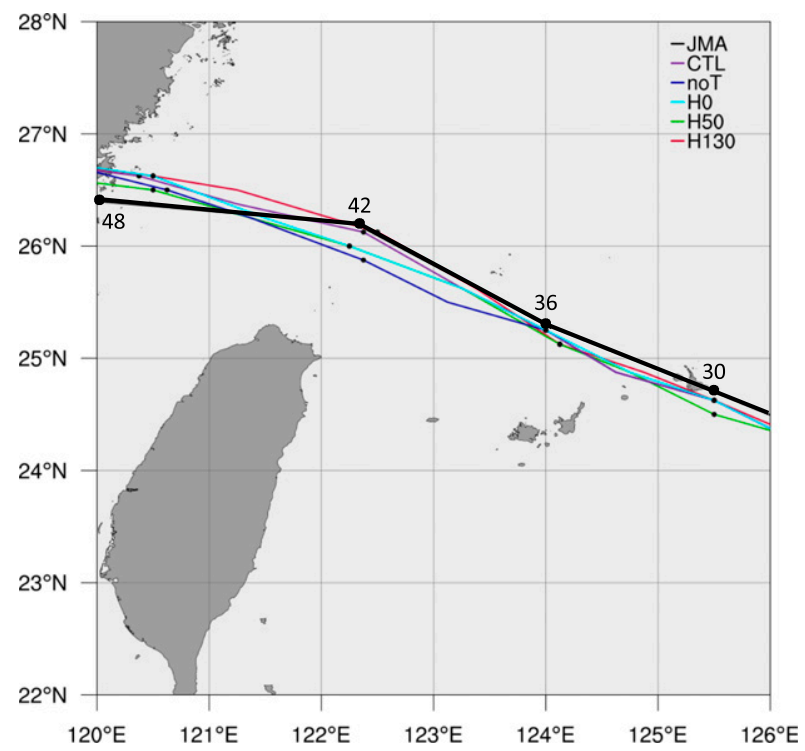

FIG. 16. The simulated tracks for CTL (purple), noT (blue), H0 (cyan), H50 (green), and H130 (red), and the JMA best track (thick black). Taiwan terrain heights are multiplied by $0 \%, 50 \%$, and $130 \%$ in $\mathrm{H} 0, \mathrm{H} 50$, and $\mathrm{H} 130$, respectively, while noT completely resets Taiwan terrain in CTL to ocean type. The numbers indicate the forecast hours.

constant $f$ plane at $23.5^{\circ} \mathrm{N}$ where the approximated peak of the CMR is located. The model initial conditions are obtained from a specified tropical sounding that is conditionally stable in the lower troposphere with a uniform relative humidity of $90 \%$ below 1-km height. The details of the environmental wind in thermal-wind balance can be found in Huang et al. (2016). The initial sea surface temperature is set to $300.15 \mathrm{~K}$ and is fixed during the total 60 -h model integration.

\section{b. Vortex initialization and experiments}

The static vortex initialization is based on a gradient-wind balance of the initial vortex (Nolan 2011; Stern and Nolan 2011). Following Huang et al. (2016), the vortex circulation is superimposed onto the steering flow at the initial time. Since the simulations are conducted on a constant $f$ plane, the steering flow can be simply specified to be easterly at a speed of $6 \mathrm{~m} \mathrm{~s}^{-1}$, which is determined from the observed translation speed of Maria prior to track deflection. We only consider two different cyclones at a maximum tangential wind speed $\left(V_{\max }\right)$ of 30 or $50 \mathrm{~m} \mathrm{~s}^{-1}$, with a smaller or larger vortex core at the radius of $V_{\max }\left(R_{\max }\right)$ equal to 100 or $150 \mathrm{~km}$.

In the idealized experiments, a mountain range is prescribed by a modified Gaussian function, where the wider tail is cut to preserve the steep slope. The mountain range embedded in an island consists of a central peak at a height of $3500 \mathrm{~m}$ and a full length of $500 \mathrm{~km}$ and width of $150 \mathrm{~km}$ that approximate those of the CMR. In this study, the idealized mountain range is not rotated so that the specified easterly steering flow is just the component of the typhoon translation normal to the orientation of the CMR. The outer and inner grid meshes, each with $301 \times 301$ grids, are employed at a uniform interval of 15 and
$5 \mathrm{~km}$, respectively. The vortex center and mountain peak are located on $(x, y)$ grids of $(190,170)$ and $(130,150)$ in the outer domain, respectively, and thus initially they are apart by $900 \mathrm{~km}$. For the experiments with $V_{\max }$ of 30 and $50 \mathrm{~m} \mathrm{~s}^{-1}$, the time evolution of the cyclone intensity shows maximum variations of about $5 \%$ and $20 \%$ decays in the first $18 \mathrm{~h}$ due to the vortex adjustment in the presence of an Ekman layer (Huang et al. 2020), then followed by a gradual increase to about $50-65 \mathrm{~m} \mathrm{~s}^{-1}$ and $70-80 \mathrm{~m} \mathrm{~s}^{-1}$, respectively, at a rate of $20 \mathrm{~m} \mathrm{~s}^{-1}$ per day (figures not shown). It should be noted that translating cyclones over a warm ocean would gradually intensify with eyewall contraction (e.g., Stern et al. 2015; Huang et al. 2020). Consequently, use of a considerably larger $R_{\max }$ turns out to increase the outward extent of the vortex core, but with similar developed RMW at later times.

\section{c. Tracks of sensitivity experiments}

Figure 17 shows the simulated 60 -h tracks of idealized experiments with initial stronger and weaker westbound cyclones that depart at different $y$ grids (in the north-south direction) of the outer domain. All the cyclones keep quite straight westward movement for first $36 \mathrm{~h}$ and afterward exhibit some track deflection as they move closer to the terrain. Similar northward track deflection for northwestward TCs on $\beta$ plane approaching offshore northeast of Taiwan was also found in other idealized experiments (e.g., Tang and Chan 2016b). The track deflection of the approaching vortex tends to occur farther westward with a larger initial meridional departure distance from the terrain. For V50R100 $\left(V_{\max }=50 \mathrm{~m} \mathrm{~s}^{-1}\right.$ and $R_{\max }=$ $100 \mathrm{~km})$, the track reaches a maximum northward deflection for a departure at $Y=174$ (174th grid in the north-south direction in the outer domain, $120 \mathrm{~km}$ northward of the northern tip of the coastline) compared to the track in the absence of the terrain (Fig. 17a). Lowering the meridional departure position does not result in a considerably enhanced northward deflection. Instead, the track deflects slightly southward after passage over the northern tip of the terrain. The track appears to take an earlier upstream deflection with a lowered meridional departure position. When the vortex core size is increased to $R_{\text {max }}=150 \mathrm{~km}$, the track deflection remains similar to that with $R_{\text {max }}=100 \mathrm{~km}$, except for Y178 $(180 \mathrm{~km}$ northward of the northern tip of the coastline) (Fig. 17b). The larger track deflection at later stages with $R_{\max }=100 \mathrm{~km}$ than that with $R_{\max }=150 \mathrm{~km}$ is also found in the ocean-only experiment. Over the ocean, the cyclone will tend to gradually intensify in association with eyewall contraction and developed asymmetric convection. Consequently, the initial larger vortex core size of $R_{\max }=150 \mathrm{~km}$ gives a slightly wider vortex circulation with stronger northerly flow northwest of the vortex center than that with $R_{\max }=100 \mathrm{~km}$, which acts to reduce the northward deflection (not shown). It should be noted that the later northward deviation is not caused by the lateral boundary conditions of the nested fine domain. We found that use of a larger inner domain also gives similar track deviations at later times. This can be partially related to the developed asymmetric convection associated with the very intense vortex at a maximum intensity as high as $80 \mathrm{~ms}^{-1}$. Nevertheless, the slowly developing cyclone during the passage near offshore of 

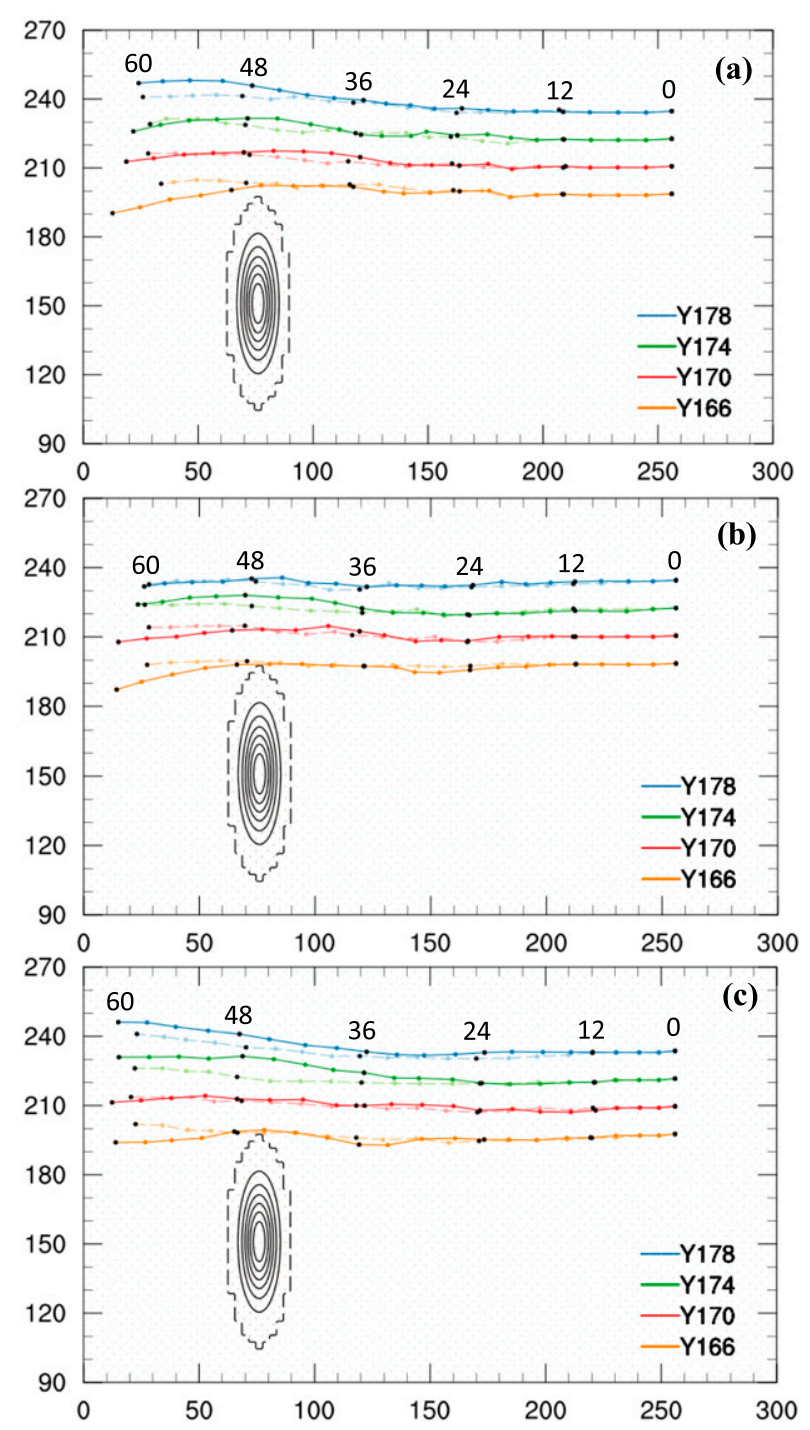

FIG. 17. Simulated tracks with different departing vortices (Y178, Y174, Y170, and Y166) for idealized experiments (a) V50R100, (b) V50R150, and (c) V30R150. The solid line and dashed line represent the tracks with and without the terrain. Bold solid contours in black represent terrain heights at an interval of $500 \mathrm{~m}$, and the dashed contour in black indicates the coastline. Solid points in the tracks are the positions of the vortex venter at in interval of $3 \mathrm{~h}$ and the numbers indicate the forecast hours. The coordinates are grids of the inner domain at an interval of $5 \mathrm{~km}$. The coordinates are grids of the inner domain at an interval of $5 \mathrm{~km}$.

northern terrain can still be viewed as a quasi-steady cyclone so that the track deflection in response to the topographic influence can be identified more easily by comparison to that under the ocean-only condition.

For weaker cyclones of V30R150 $\left(V_{\max }=30 \mathrm{~m} \mathrm{~s}^{-1}\right.$ and $R_{\text {max }}=150 \mathrm{~km}$ ), maximum northward track deflection is also induced for Y174, while the track after passing around the northern terrain for Y166 becomes southward of that without the terrain, similar to the stronger case. For Y174, the northward track deflection of weaker cyclones is stronger and occurs farther upstream than that of stronger cyclones (Fig. 17c). Near the deflection time, Maria in the real case produces a maximum wind speed of about $55 \mathrm{~m} \mathrm{~s}^{-1}$ near the surface and over $75 \mathrm{~m} \mathrm{~s}^{-1}$ above 1-km height (see Fig. 15) associated with a northward deviation of $50 \mathrm{~km}$ at a length scale of about $300 \mathrm{~km}$. The idealized experiments for V50 (stronger cyclone) and V30 (weaker cyclone) give track deflection with a maximum deviation of 40 and $50 \mathrm{~km}$ at a length scale of about 300 and $500 \mathrm{~km}$, respectively. Thus, the observed northward track deflection is reasonably emulated by the idealized modeling with similar terrain and a translating vortex.

\section{d. Track deflection mechanism}

To understand the flow structure leading to the difference in the induced track deflection, Fig. 18 shows the simulated wind fields at $850 \mathrm{hPa}$ at 36 and $39 \mathrm{~h}$ for V50R150 with the initial vortex at the 174th and 170th $y$ grids (denoted as V50R150-Y174 and V50R150-Y170, respectively) as well as V50R100-Y166. In general, the differences in the wind fields are not large for these experiments. At $36 \mathrm{~h}$, the wind induced by the topographic effects for V50R100-Y166 is more southerly east of the terrain and southeast of the vortex center (Fig. 18e versus Fig. 18a). For V50R150-Y170, the southerly wind is slightly stronger southeast of the vortex center (Fig. 18c) as to induce a larger deflection on track more upstream at this time than V50R100-Y166 (Fig. 17e). At $39 \mathrm{~h}$, the track deflection for V50R150-Y174 is largest with the developed strongest southerly wind at the southeast quadrant as indicated by the white dashed circle (Fig. 18b). The southerly wind southeast of the vortex center is also stronger for V50R150-Y170 (Fig. 18d) than V50R100-Y166 (Fig. 18f), thus producing a larger track deflection (see Fig. 17b). The track for Y166 has resumed to the earlier westward direction at $39 \mathrm{~h}$ with the weakest southerly wind at the southeast quadrant of the vortex as well as more symmetric development of the wind structure to the west and east of the vortex center (Fig. 18f). Such enhanced wind symmetry of the vortex for Y166 greatly reduces the northward movement of the vortex when approaching closer to the northern tip of the terrain. It is also noted that the size of the intense vortex core is smallest at 36 and $39 \mathrm{~h}$ for Y166 with R100 compared to both Y170 and Y174 with R150.

The total wind fields for different experiments in Fig. 18 exhibit no significantly large differences as their associated tracks are not largely deviated as well. The structures of WN-1 horizontal wind averaged from 1- to 8-km height are analyzed and are shown in Fig. 19 for the same three experiments (denoted as Y174, Y170 and Y166). Weaker WN-1 wind is produced in the inner vortex, but distributed with a prominent elongation mainly east-westward. Note that there is a pair of minimum wind speed zones in the $\mathrm{WN}-1$ wind, but with reverse phases of flow direction. The WN-1 stronger wind surrounding the WN-1 weak-wind zones may help explain the movement of the vortex in response to the asymmetric flow. The WN-1 weak-wind zones are mainly oriented west-northwestward forY174 and Y166 and westward for Y170 at 36 h, but Y174 produces the largest zones and Y166 the smallest. At $39 \mathrm{~h}$, the WN-1 weak-wind zones with nearly the same orientation for 

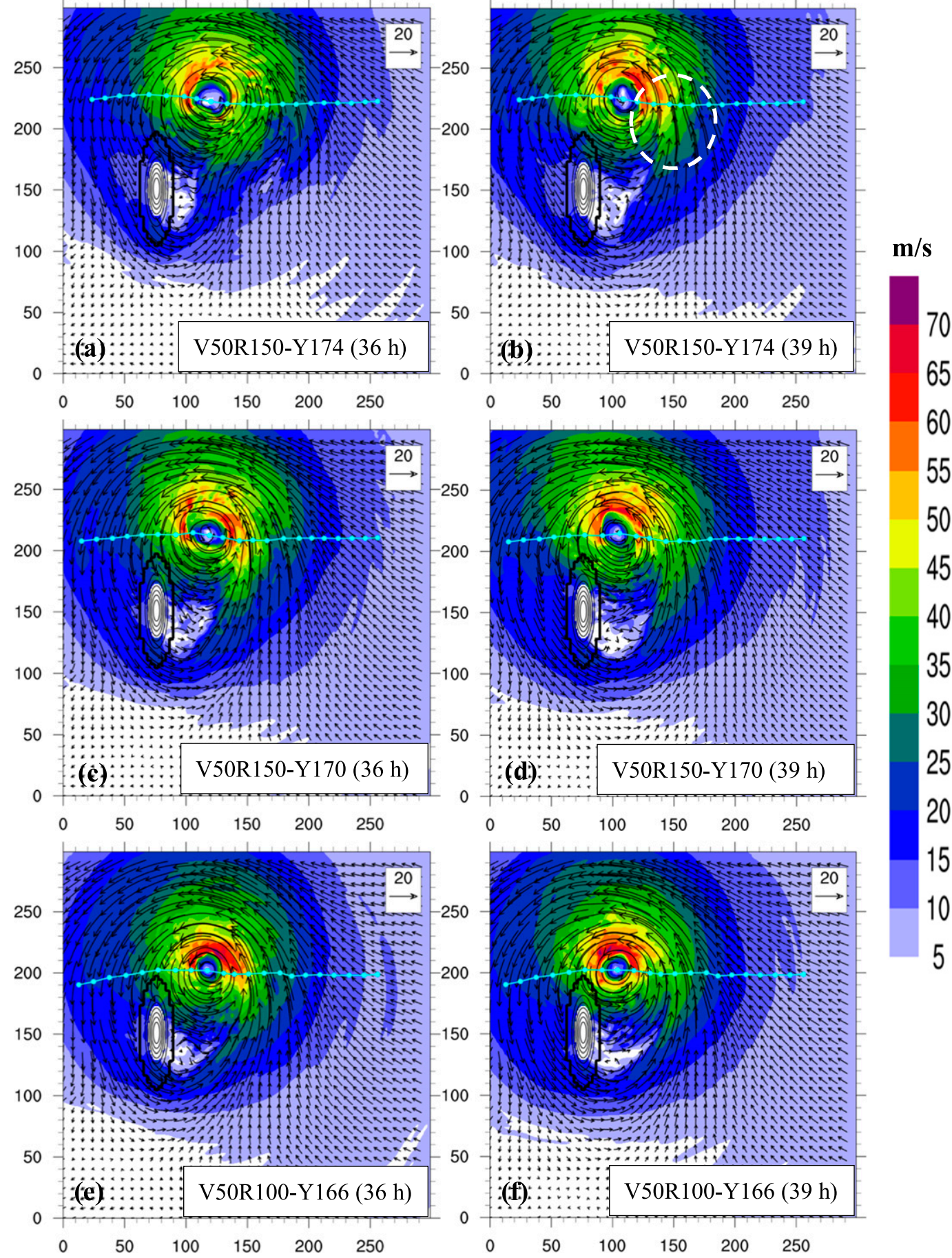

FIG. 18. (a) Horizontal wind (vectors; $\mathrm{m} \mathrm{s}^{-1}$ ) and wind speed (shaded colors; $\mathrm{m} \mathrm{s}^{-1}$ ) at $850 \mathrm{hPa}$ at $36 \mathrm{~h}$ with the initial departing vortex at the 174th north-south grid (Y174) for V50R150. (b) As in (a), but at $39 \mathrm{~h}$. (c), (d) As in (a) and (b), but at 170th north-south grid (Y170), respectively. (e),(f) As in (a) and (b), but for V50R100 at 166th north-south grid (Y166), respectively. The white circle marked in (b) indicates the stronger wind zone at $39 \mathrm{~h}$ than the two other cases. The track in cyan is overlaid with solid dots at an interval of $3 \mathrm{~h}$. The coordinates are grids of the inner domain at an interval of $5 \mathrm{~km}$. 

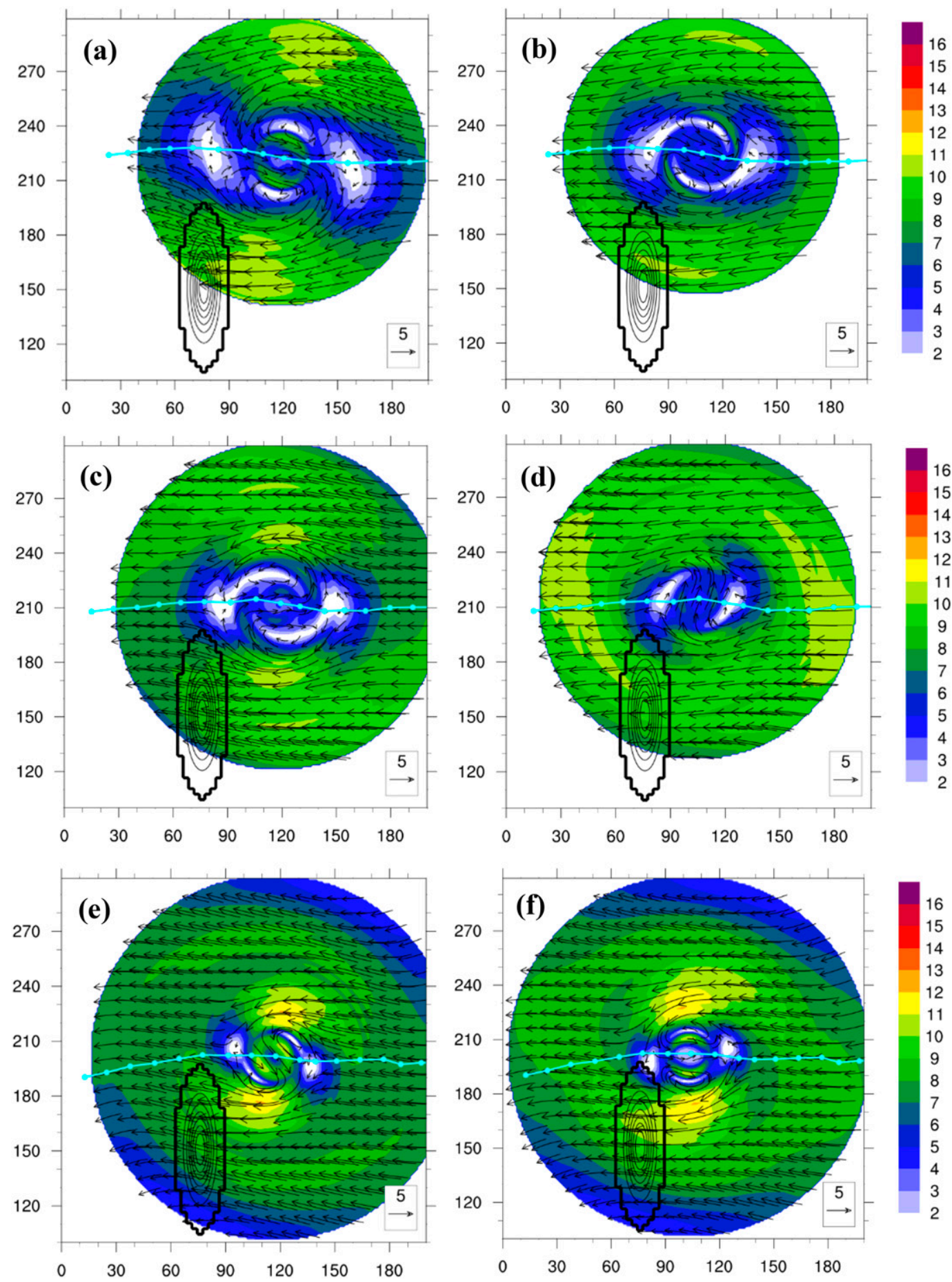

FIG. 19. As in Fig. 18, but for wavenumber-1 horizontal wind $\left(\mathrm{m} \mathrm{s}^{-1}\right)$ averaged from 1- to 8-km height.

Y174 is significantly larger than both Y170 and Y166. Y166 now gives a west-east orientation of the $\mathrm{WN}-1$ weak-wind zones (Fig. 19f). The east-west wind symmetry as seen at $850 \mathrm{hPa}$ (see Fig. 18f) remains evident in the WN-1 deep-layer flow for Y166. Indeed, there is stronger wind just north and south of the vortex center for Y166. Consequently, the track is more westward for Y166 after $39 \mathrm{~h}$ and even becomes slightly southward after passing by the northern tip of the terrain. It is noted that such steering flow roughly indicated by the orientation of the $\mathrm{WN}-1$ weak-wind zones in the idealized experiments also appears in the real case of Maria as shown in Fig. 14. 

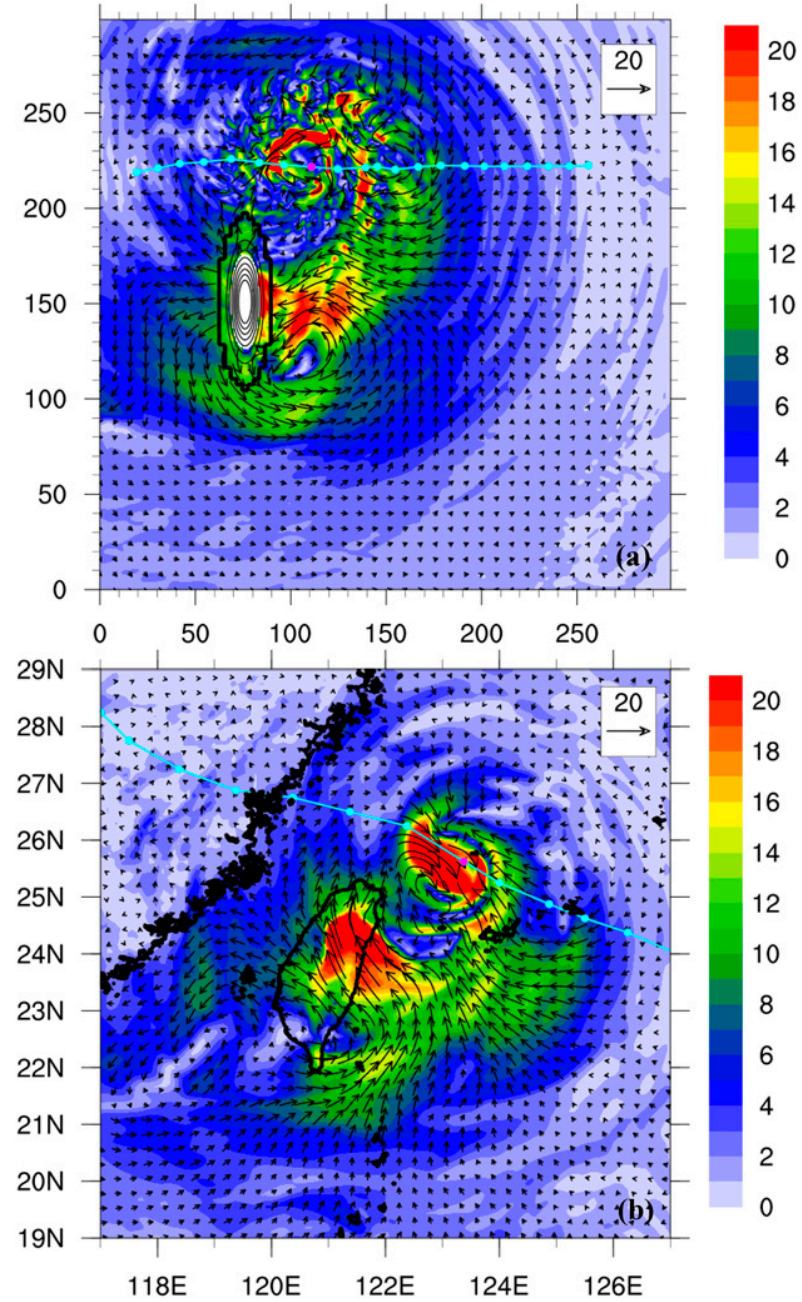

FIG. 20. (a) The differences in the horizontal wind vector $\left(\mathrm{m} \mathrm{s}^{-1}\right)$ and wind speed (shaded colors; $\mathrm{m} \mathrm{s}^{-1}$ ) at $850 \mathrm{hPa}$ at $39 \mathrm{~h}$ for the experiments of V50R150-Y174 with the $130 \%$ terrain height and ocean only, where the track in cyan for the former is overlaid. The coordinates are grids of the inner domain at an interval of $5 \mathrm{~km}$. (b) As in (a), but at $39 \mathrm{~h}$ for the real case of Maria.

There is not necessarily a larger induced northward track deflection for the idealized westbound vortex when the terrain (with a maximum height of $3.5 \mathrm{~km}$ ) becomes even higher, consistent with the real-case simulation. Since V50R150-Y174 has shown the largest track deflection, it is used for the sensitivity test on terrain height that is increased by $30 \%$. Figure 20 shows the simulated track for this terrain-sensitivity experiment and the flow differences at $850 \mathrm{hPa}$ at $39 \mathrm{~h}$ from the corresponding ocean-only simulation. The flow differences between the $100 \%$ terrain and ocean-only idealized experiments are similar and are not shown in Fig. 20. Note that the track is slightly less northward near offshore of the northern terrain when the terrain height is increased to $130 \%$. The flow differences from the ocean-only experiments for both real and idealized experiments with $130 \%$ and $100 \%$ terrain heights are very similar, showing a pair of similar topographically induced gyres with smaller anticyclonic and larger cyclonic vortices to the east and farther south of the vortex center, respectively. The induced gyres in the idealized experiments (Fig. 20a) provide west-northwestward flow to the southeast of the vortex center and thus favor a west-northwestward movement of the vortex at this time. On the other hand, it can be seen that the flow differences at $850 \mathrm{hPa}$ at $39 \mathrm{~h}$ between CTL and noT for the real case of Maria also exhibit a pair of similar gyres but with roughly northwestward flow farther south of the vortex center (Fig. 20b). The larger northward orientation of the gyres in the real case is intimately related to the west-northwestward track compared to the westward track in the idealized case. The track deflection of the real case is reasonably emulated by the idealized case, suggesting a pronounced role of Taiwan terrain in the induced track deflection of Maria.

\section{Conclusions}

Typhoon Maria (2018) took a northward track deflection when moving west-northwestward offshore close to northern Taiwan. In this study, the global model FV3GFS has been used to simulate the track and intensity evolution of Maria prior to and during passage near Taiwan. FV3GFS provides a cubed sphere with enhanced horizontal resolution by stretching the grids on a targeted face centered at Taiwan. The simulation results show that the performance using stretched grids of approximately $7-\mathrm{km}$ resolution outperforms that using unstretched grids of $13-\mathrm{km}$ resolution, in particular, for typhoon intensity prediction. The model reasonably captures the observed northward track deflection and intensity evolution of the typhoon when moving closer to northern Taiwan.

The simulation results indicate that the northward track deflection of Maria is in response to the topographic influence of Taiwan terrain where the Central Mountain Range (CMR) at a maximum height of about $3.5 \mathrm{~km}$ is aligned roughly in the north-south direction. As the typhoon vortex core approaches to about $150 \mathrm{~km}$ offshore northeast of Taiwan, the outer cyclonic flow of the vortex at low levels is split around the northern CMR and induces the southwesterly to southerly flow east of Taiwan from its recirculating flow around the southern corner of the CMR. The southerly inflow east of Taiwan becomes more intense inward into the inner typhoon vortex and converges with the westerly flow of the inner vortex at the southern flank of the vortex as the typhoon is closer to northern Taiwan. Such strong convergence leads to a northward deflection of the west-northwestward typhoon track with the stronger wind to the east of the vortex center. The radial inflow at low levels intensified south of the vortex center transports larger angular momentum (AM) inward with the enhanced upward motions and positive vertical mean AM advection to increase the azimuthal mean tangential wind in the lowertropospheric eyewall. Diagnostics of decomposed WN-1 vorticity budget terms indicate that horizontal vorticity advection gives the dominant contribution to positive vorticity tendency mainly at the northwest quadrant of the vortex, while the other three terms (vertical advection, stretching and tilting) are relatively minor. Sensitivity experiments on both physics parameterization and terrain height identify the dominance of 
topographic influence on the northward track deflection, which otherwise will not be induced, regardless of use of cloud microphysics and convection schemes, if Taiwan terrain is removed. On the other hand, the experiment with 130\% Taiwan terrain height only gives a very small increase in northward deflection, while flattening the terrain considerably weakens the deflection, but not completely.

Idealized experiments using the regional model WRF also support the mechanism of northward track deflection as in the real case as westward tropical cyclones approach near offshore of a mountain range similar to the CMR. The track deflection takes place northeast and offshore of the terrain in response to the developed asymmetric southerly flow at the southeast quadrant of the vortex, east of the terrain. It was found that flow differences between the experiments with and without the terrain show a pair of similar topographically induced gyres with smaller anticyclonic and larger cyclonic vortices to the east and farther south of the vortex center, respectively, which thus facilitate an increased northward movement of the vortex. When the initial vortex is weaker, the northward deflection becomes stronger and farther upstream at earlier times. The northward track deflection is also dependent on the meridional departure position of the initial westbound vortex. An initial position of the vortex center about $120 \mathrm{~km}$ northward of the northern coastline appears to induce a larger northward deflection. However, the northward deflection is significantly reduced by a further increase of the meridional departure to $180 \mathrm{~km}$. In addition, the track deflection is not increased as well as the approaching vortex is moved closer to the northern tip of the mountain range, due to the enhanced east-west symmetry of wind structure in the inner vortex. As a result, there exists an optimal position of offshore passage with a maximum northward track deflection. The track deflection is also not amplified as the mountain height is increased to $130 \%$ in both real and idealized cases, indicating that the recirculating flow at low levels around the southern mountain range is more dominant but cannot be notably enhanced by the higher mountain (up to $4.55-\mathrm{km}$ height in the idealized case).

This study discusses several important aspects of the track deflection associated with an approaching TC near offshore of a mountain range. A modified form of nondimensional number $\left(R / L_{y}\right)$, where $R$ is the radius of RMW and $L_{y}$ is the length scale of the mountain in the direction normal to the TC movement, has been proposed by a prior study to explain the track deflection of TCs past and around Réunion Island (Barbary et al. 2019). As mentioned in the introduction, this nondimensional number, however, is better suited for TCs impinging upon the major part of a mountain with appreciable upstream blocking (Lin et al. 2005; Huang et al. 2016). Both real-case simulations and idealized simulations in this study highlight the important role of the recirculating flow around the southern terrain periphery in the upstream northward track deflection and suggest the offshore distance of the vortex core from the terrain to be a candidate parameter in possible nondimensional formulation. It will be intriguing to investigate nondimensional numbers controlling the track deflection of TCs passing near offshore of a mountain range in a future study.
Acknowledgments. This study was supported by the Ministry of Science and Technology (MOST) in Taiwan. We appreciate Dr. D. Nolan for his idealized WRF codes for use. Dr. Y.-H. Chen helped on FV3GFS implementation at CWB in Taiwan. CWB provided the computation quota and disk facility for the FV3GFS simulations in this study.

\section{APPENDIX}

\section{Formulation of Angular Momentum Budget}

The governing equations for radial velocity $u$ and tangential velocity $v$ in cylindrical coordinates $(\lambda, r, z)$ (azimuthal angle $\lambda$, radius $r$, height $z$ ) can be given, respectively, by

$$
\begin{aligned}
& \frac{\partial u}{\partial t}+u \frac{\partial u}{\partial r}+\frac{v}{r} \frac{\partial u}{\partial \lambda}+w \frac{\partial u}{\partial z}=f v+\frac{v^{2}}{r}-\frac{1}{\rho} \frac{\partial p}{\partial r}+F_{u}, \\
& \frac{\partial v}{\partial t}+u \frac{\partial v}{\partial r}+\frac{v}{r} \frac{\partial v}{\partial \lambda}+w \frac{\partial v}{\partial z}=-f u-\frac{u v}{r}-\frac{1}{\rho r} \frac{\partial p}{\partial \lambda}+F_{v},
\end{aligned}
$$

where $F_{u}$ and $F_{v}$ are turbulent diffusion terms in the boundary layer.

A tangential-wind tendency budget (A2) can be used to diagnose the vortex evolution (e.g., Yau et al. 2004). For consideration on conservation, angular momentum (AM) $(M=r v)$ is applied to analyze the flow tendency. The tendency equation of $\mathrm{AM}$ is derived using (A2) as

$$
\frac{D M}{D t}=\frac{\partial r v}{\partial t}+u \frac{\partial r v}{\partial r}+\frac{v}{r} \frac{\partial r v}{\partial \lambda}+w \frac{\partial r v}{\partial z}=-r\left(f u-\frac{1}{\rho r} \frac{\partial p}{\partial \lambda}+F_{v}\right) .
$$

From (A3), it can be shown that the absolute angular momentum $\left[M_{a}=M+(1 / 2) f^{2}\right]$ will be conserved following the frictionless motion in the absence of an azimuthal pressure gradient force (Zhang et al. 2001). Decomposing (A3) with $u=\bar{u}+u^{\prime}, v=$ $\bar{v}+v^{\prime}, w=\bar{w}+w^{\prime}, \rho=\bar{\rho}+\rho^{\prime}$, and $p=\bar{p}+p^{\prime}$, where an overbar (prime) is the azimuthal mean (deviation) of a variable and then taking the azimuthal mean of all the decomposed terms will give

$$
\frac{\partial r \bar{v}}{\partial t}+\bar{u} \frac{\partial r \bar{v}}{\partial r}+\bar{w} \frac{\partial r \bar{v}}{\partial z}=-r f \bar{u}+r \bar{F}_{v}+r \overline{\frac{\rho^{\prime}}{\bar{\rho}^{2}} \frac{\partial p^{\prime}}{r \partial \lambda}}-\overline{u^{\prime} \frac{\partial r v^{\prime}}{\partial r}}-\overline{w^{\prime} \frac{\partial r v^{\prime}}{\partial z}}
$$

which indicates that Lagrangian mean angular momentum (lefthand side) can be changed through torques exerted by the mean Coriolis force, turbulent frictional force and correlation between the asymmetric tangential pressure gradient force and density perturbation, as well as the radial and vertical advection of the asymmetric eddy angular momentum. Normally, the effect of mean asymmetric tangential pressure gradient force associated with small density deviations can be ignored as compared to the other terms. Equation (A4) is similar to the tendency equation of azimuthal mean tangential wind used by Smith et al. (2017).

\section{REFERENCES}

Barbary, D., M.-D. Leroux, and O. Bousquet, 2019: The orographic effect of Reunion Island on tropical cyclone track 
and intensity. Atmos. Sci. Lett., 20, e882, https://doi.org/ 10.1002/asl.882.

Bender, M. A., R. E. Tuleya, and Y. Kurihara, 1987: A numerical study of the effect of an island terrain on tropical cyclones. Mon. Wea. Rev., 115, 130-155, https://doi.org/ 10.1175/1520-0493(1987)115<0130:ANSOTE > 2.0.CO;2.

Chambers, C. R. S., and T. Li, 2011: The effect of Hawai'i's Big Island on track and structure of tropical cyclones passing to the south and west. Mon. Wea. Rev., 139, 3609-3627, https:// doi.org/10.1175/MWR-D-11-00031.1.

Chang, C.-P., Y.-T. Yang, and H.-C. Kuo, 2013: Large increasing trend of tropical cyclone rainfall in Taiwan and the roles of terrain. J. Climate, 26, 4138-4147, https://doi.org/10.1175/ JCLI-D-12-00463.1.

Chang, S. W.-J., 1982: The orographic effects induced by an island mountain range on propagating tropical cyclones. Mon. Wea. Rev., 110, 1255-1270, https://doi.org/10.1175/1520-0493(1982) $110<1255$ :TOEIBA $>2.0 . \mathrm{CO} ; 2$.

Chen, J.-H., and Coauthors, 2019: Advancements in hurricane prediction with NOAA's next-generation forecast system. Geophys. Res. Lett., 46, 4495-4501, https://doi.org/10.1029/ 2019GL082410.

Chen, Y.-H., H.-C. Kuo, C.-C. Wang, and Y.-T. Yang, 2017: Influence of southwest monsoon flow and typhoon track on Taiwan rainfall during the exit phase: Modelling study of Typhoon Morakot (2009). Quart. J. Roy. Meteor. Soc., 143, 3014-3024, https://doi.org/10.1002/qj.3156.

Chien, F. C., and H. C. Kuo, 2011: On the extreme rainfall of Typhoon Morakot (2009). J. Geophys. Res., 116, D05104, https://doi.org/10.1029/2010JD015092.

Han, J., and H.-L. Pan, 2011: Revision of convection and vertical diffusion schemes in the NCEP Global Forecast System. Wea. Forecasting, 26, 520-533, https://doi.org/ 10.1175/WAF-D-10-05038.1.

—, W. Wang, Y. C. Kwon, S. Hong, V. Tallapragada, and F. Yang, 2017: Updates in the NCEP GFS cumulus convection schemes with scale and aerosol awareness. Wea. Forecasting, 32, 2005-2017, https://doi.org/10.1175/WAF-D-17-0046.1.

Harris, L. M., and S.-J. Lin, 2013: A two-way nested global-regional dynamical core on the cubed-sphere grid. Mon. Wea. Rev., 141, 283-306, https://doi.org/10.1175/MWR-D-11-00201.1.

,-- , and C. Tu, 2016: High-resolution climate simulations using GFDL HiRAM with a stretched global grid. J. Climate, 29, 4293-4314, https://doi.org/10.1175/JCLI-D-15-0389.1.

Hazelton, A. T., L. Harris, and S.-J. Lin, 2018a: Evaluation of tropical cyclone structure forecasts in a high-resolution version of the multiscale GFDL fvGFS model. Wea. Forecasting, 33, 419-442, https://doi.org/10.1175/WAF-D-17-0140.1.

_- M. Bender, M. Morin, L. Harris, and S.-J. Lin, 2018b: 2017 Atlantic hurricane forecasts from a high-resolution version of the GFDL fvGFS model: Evaluation of track, intensity, and structure. Wea. Forecasting, 33, 1317-1337, https://doi.org/ 10.1175/WAF-D-18-0056.1.

Hsu, L.-H., H.-C. Kuo, and R. G. Fovell, 2013: On the geographic asymmetry of typhoon translation speed across the mountainous island of Taiwan. J. Atmos. Sci., 70, 1006-1022, https:// doi.org/10.1175/JAS-D-12-0173.1.

- - , S.-H. Su, R. G. Fovell, and H.-C. Kuo, 2018: On typhoon track deflections near the east coast of Taiwan. Mon. Wea. Rev., 146, 1495-1510, https://doi.org/10.1175/ MWR-D-17-0208.1.

Huang, C.-Y., C.-A. Chen, S.-H. Chen, and D. S. Nolan, 2016: On the upstream track deflection of tropical cyclones past a mountain range: Idealized experiments. J. Atmos. Sci., 73, 3157-3180, https://doi.org/10.1175/JAS-D-15-0218.1.

_, Y. Zhang, W. C. Skamarock, and L.-F. Hsu, 2017: Influences of large-scale flow variations on the track evolution of Typhoons Morakot (2009) and Megi (2010): Simulations with a global variable-resolution model. Mon. Wea. Rev., 145, 1691-1716, https://doi.org/10.1175/MWR-D-16-0363.1.

_ C.-H. Huang, and W. C. Skamarock, 2019: Track deflection of Typhoon Nesat (2017) as realized by multiresolution simulations of a global model. Mon. Wea. Rev., 147, 1593-1613, https://doi.org/10.1175/MWR-D-18-0275.1.

—, C.-W. Chou, S.-H. Chen, and J.-H. Xie, 2020: Topographic rainfall of tropical cyclones past a mountain range as categorized by idealized simulations. Wea. Forecasting, 35, 25-49, https://doi.org/10.1175/WAF-D-19-0120.1.

Huang, K.-C., and C.-C. Wu, 2018: The impact of idealized terrain on upstream tropical cyclone track. J. Atmos. Sci., 75, 3887-3910, https://doi.org/10.1175/JAS-D-18-0099.1.

Huang, Y.-H., C.-C. Wu, and Y. Wang, 2011: The influence of island topography on typhoon track deflection. Mon. Wea. Rev., 139, 1708-1727, https://doi.org/10.1175/2011MWR3560.1.

Jian, G.-J., and C.-C. Wu, 2008: A numerical study of the track deflection of Supertyphoon Haitang (2005) prior to its landfall in Taiwan. Mon. Wea. Rev., 136, 598-615, https://doi.org/ 10.1175/2007MWR2134.1.

Lin, S. J., 1997: A finite-volume integration method for computing pressure gradient force in general vertical coordinates. Quart. J. Roy. Meteor. Soc., 123, 1749-1762, https://doi.org/10.1002/ QJ.49712354214.

Lin, S.-J., 2004: A "vertically Lagrangian" finite-volume dynamical core for global models. Mon. Wea. Rev., 132, 2293-2307, https:// doi.org/10.1175/1520-0493(2004)132<2293:AVLFDC>2.0.CO;2.

_ , and R. B. Rood, 1996: Multidimensional flux-form semiLagrangian transport schemes. Mon. Wea. Rev., 124, 2046-2070, https://doi.org/10.1175/1520-0493(1996)124<2046:MFFSLT> 2.0.CO;2.

— shallow-water model on the sphere. Quart. J. Roy. Meteor. Soc., 123, 2477-2498, https://doi.org/10.1002/qj.49712354416.

Lin, Y.-L., and L. C. Savage, 2011: Effects of landfall location and the approach angle of a cyclone vortex encountering a mesoscale mountain range. J. Atmos. Sci., 68, 2095-2106, https:// doi.org/10.1175/2011JAS3720.1.

_ R. D. Farley, and H. D. Orville, 1983: Bulk parameterization of the snow field in a cloud model. J. Climate Appl. Meteor., 22, 1065-1092, https://doi.org/10.1175/1520-0450(1983)022<1065: BPOTSF $>2.0 . C O ; 2$.

— J. Han, D. W. Hamilton, and C.-Y. Huang, 1999: Orographic influence on a drifting cyclone. J. Atmos. Sci., 56, 534-562, https:// doi.org/10.1175/1520-0469(1999)056<0534:OIOADC>2.0.CO;2.

, D. B. Ensley, S. Chiao, and C.-Y. Huang, 2002: Orographic influences on rainfall and track deflection associated with the passage of a tropical cyclone. Mon. Wea. Rev., 130, 2929-2950, https://doi.org/10.1175/1520-0493(2002)130<2929: OIORAT $>2.0 . \mathrm{CO} ; 2$.

— , S.-Y. Chen, C. M. Hill, and C.-Y. Huang, 2005: Control parameters for the influence of a mesoscale mountain range on cyclone track continuity and deflection. J. Atmos. Sci., 62, 1849-1866, https://doi.org/10.1175/JAS3439.1.

- , S.-H. Chen, and L. Liu, 2016: Orographic influence on basic flow and cyclone circulation and their impacts on track deflection of an idealized tropical cyclone. J. Atmos. Sci., 73, 3951-3974, https://doi.org/10.1175/JAS-D-15-0252.1. 
Nolan, D. S., 2011: Evaluating environmental favorableness for tropical cyclone development with the method of pointdownscaling. J. Adv. Model. Earth Syst., 3, M08001, https:// doi.org/10.1029/2011MS000063.

Putman, W. M., and S.-J. Lin, 2007: Finite-volume transport on various cubed-sphere grids. J. Comput. Phys., 227, 55-78, https://doi.org/10.1016/j.jcp.2007.07.022.

Skamarock, W. C., and Coauthors, 2008: A description of the Advanced Research WRF version 3. NCAR Tech. Note NCAR/TN475+STR, 113 pp., https://doi.org/10.5065/D68S4MVH.

Smith, R. K., J. A. Zhang, and M. T. Montgomery, 2017: The dynamics of intensification in a Hurricane Weather Research and Forecasting simulation of Hurricane Earl (2010). Quart. J. Roy. Meteor. Soc., 143, 293-308, https://doi.org/10.1002/qj.2922.

Stern, D. P., and D. S. Nolan, 2011: On the vertical decay rate of the maximum tangential winds in tropical cyclones. J. Atmos. Sci., 68, 2073-2094, https://doi.org/10.1175/2011JAS3682.1.

_ - J. L. Vigh, D. S. Nolan, and F. Zhang, 2015: Revisiting the relationship between eyewall contraction and intensification. J. Atmos. Sci., 72, 1283-1306, https://doi.org/10.1175/ JAS-D-14-0261.1.

Tang, C. K., and J. C. L. Chan, 2016a: Idealized simulations of the effect of Taiwan topography on the tracks of tropical cyclones with different sizes. Quart. J. Roy. Meteor. Soc., 142, 793-804, https://doi.org/10.1002/qj.2681.

, and $-2016 \mathrm{~b}$ : Idealized simulations of the effect of Taiwan topography on the tracks of tropical cyclones with different steering flow strengths. Quart. J. Roy. Meteor. Soc., 142, 3211-3221, https://doi.org/10.1002/qj.2902.
Wu, C.-C., T.-H. Li, and Y.-H. Huang, 2015: Influence of mesoscale topography on tropical cyclone tracks: Further examination of the channeling effect. J. Atmos. Sci., 72, 3032-3050, https:// doi.org/10.1175/JAS-D-14-0168.1.

$\mathrm{Wu}, \mathrm{L}$., and B. Wang, 2000: A potential vorticity tendency diagnostic approach for tropical cyclone motion. Mon. Wea. Rev., 128, 1899-1911, https://doi.org/10.1175/1520-0493(2000)128<1899: APVTDA $>2.0 . \mathrm{CO} ; 2$.

Yau, M. K., Y. Liu, D.-L. Zhang, and Y. Chen, 2004: A multiscale numerical study of Hurricane Andrew (1992). Part VI: Small-scale inner-core structures and wind streaks. Mon. Wea. Rev., 132, 1410-1433, https://doi.org/10.1175/ 1520-0493(2004)132<1410:AMNSOH > 2.0.CO;2.

Yeh, T.-C., and R. L. Elsberry, 1993a: Interaction of typhoons with the Taiwan topography. Part I: Upstream track deflections. Mon. Wea. Rev., 121, 3193-3212, https://doi.org/ 10.1175/1520-0493(1993)121<3193:IOTWTT>2.0.CO;2.

, and $-1993 \mathrm{~b}$ : Interaction of typhoons with the Taiwan topography. Part II: Continuous and discontinuous tracks across the island. Mon. Wea. Rev., 121, 3213-3233, https://doi.org/ 10.1175/1520-0493(1993)121<3213:IOTWTT>2.0.CO;2.

Zhang, D.-L., Y. Liu, and M. Yau, 2001: A multiscale numerical study of Hurricane Andrew (1992). Part IV: Unbalanced flows. Mon. Wea. Rev., 129, 92-107, https://doi.org/10.1175/ 1520-0493(2001)129<0092:AMNSOH > 2.0.CO;2.

Zhou, L., S.-J. Lin, J.-H. Chen, L. M. Harris, X. Chen, and S. L. Rees, 2019: Toward convective-scale prediction within the next generation global prediction system. Bull. Amer. Meteor. Soc., 100, 1225-1243, https://doi.org/10.1175/BAMS-D-17-0246.1. 